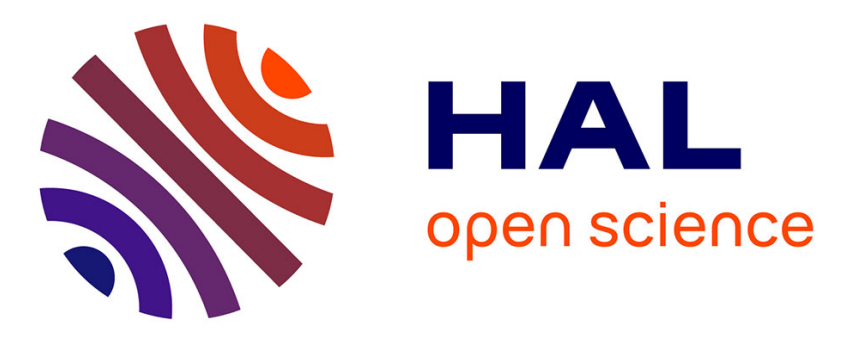

\title{
A two-surface thermomechanical plasticity model considering thermal cyclic behavior
}

Wei Cheng, Ren-Peng Chen, Peng-Yun Hong, Yu-Jun Cui, Jean-Michel Pereira

\section{- To cite this version:}

Wei Cheng, Ren-Peng Chen, Peng-Yun Hong, Yu-Jun Cui, Jean-Michel Pereira. A two-surface thermomechanical plasticity model considering thermal cyclic behavior. Acta Geotechnica, 2020, 10.1007/s11440-020-00999-5 . hal-02874658

\section{HAL Id: hal-02874658 \\ https://hal-enpc.archives-ouvertes.fr/hal-02874658}

Submitted on 19 Jun 2020

HAL is a multi-disciplinary open access archive for the deposit and dissemination of scientific research documents, whether they are published or not. The documents may come from teaching and research institutions in France or abroad, or from public or private research centers.
L'archive ouverte pluridisciplinaire HAL, est destinée au dépôt et à la diffusion de documents scientifiques de niveau recherche, publiés ou non, émanant des établissements d'enseignement et de recherche français ou étrangers, des laboratoires publics ou privés. 
3 Wei Cheng ${ }^{1}$, Ren-peng Chen ${ }^{2}$, Peng-yun Hong ${ }^{3}$, Yu-jun Cui ${ }^{4}$, Jean-Michel Pereira ${ }^{5}$

$5 \quad{ }^{1}$ Ph.D candidate, Department of Civil Engineering, Zhejiang University, Hangzhou 6310058, China, wcheng@zju.edu.cn

$7 \quad 2$ Professor, Department of Civil Engineering, Zhejiang University, Hangzhou 310058,

8 China; College of Civil Engineering, Hunan University, Changsha 410082, China;

9 chenrp@zju.edu.cn, chenrp@hnu.edu.cn

$10{ }^{3}$ Former Ph.D student, Université Paris-Est, Laboratoire Navier (UMR 8205), CNRS,

11 ENPC, IFSTTAR, F-77455 Marne-la-Vallée, France

$12{ }^{4}$ Professor, Université Paris-Est, Laboratoire Navier (UMR 8205), CNRS, ENPC,

13 IFSTTAR, F-77455 Marne-la-Vallée, France

145 Professor, Université Paris-Est, Laboratoire Navier (UMR 8205), CNRS, ENPC, 15 IFSTTAR, F-77455 Marne-la-Vallée, France

16

17

18

19 


\section{Abstract}

23 In thermal-related engineering such as thermal energy structures and nuclear waste

24 disposal, it is essential to well understand volume change and excess pore water

25 pressure buildup of soils under thermal cycles. However, most existing thermo-

26 mechanical models can merely simulate one heating-cooling cycle and fail in capturing

27 accumulation phenomenon due to multiple thermal cycles. In this study, a two surface

28 elasto-plastic model considering thermal cyclic behavior is proposed. This model is

29 based on the bounding surface plasticity and progressive plasticity by introducing two

30 yield surfaces and two loading yield limits. A dependency law is proposed by linking

31 two loading yield limits with a thermal accumulation parameter $n_{c}$, allowing the thermal

32 cyclic behavior to be taken into account. Parameter $n_{c}$ controls the evolution rate of the

33 inner loading yield limit approaching the loading yield limit following a thermal loading

34 path. By extending the thermo-hydro-mechanical equations into the elastic-plastic state,

35 the excess pore water pressure buildup of soil due to thermal cycles is also accounted.

36 Then, thermal cycle tests on four fine-grained soils (natural Boom clay, Geneva clay,

37 Bonny silt and reconstituted Pontida clay) under different OCRs and stresses are

38 simulated and compared. The results show that the proposed model can well describe

39 both strain accumulation phenomenon and excess pore water pressure buildup of fine-

40 grained soils under the effect of thermal cycles.

41 Keywords: fine-grained soils; strain accumulation; thermal cycles; two-surface model;

42 excess pore water pressure buildup 


\section{Introduction}

44 Around energy piles [1-3], nuclear waste canisters [4], buried tunnels and pipes [5], the

45 soils suffer from temperature effects, especially heating-cooling cycles. Observations

46 of different fine-grained soils in the laboratory and in the field [6-11] showed that

47 heating generally induced non-negligible volume change and excess pore water

48 pressure buildup. Several thermo-mechanical models were proposed to describe this

49 thermo-mechanical behavior of fine-grained soils [13-21]. Some of them extended the

50 Cam-clay or modified Cam-clay model to the temperature effect by introducing a

51 shrinking yield surface [13-17]. These models could describe some basic thermo-

52 mechanical behavior, but fail to describe the soil behavior in over-consolidated states.

53 In order to well describe the small thermo-mechanical elastic zone and the shear

54 softening behavior, some advanced models consider two yield surfaces based on the

55 bounding surface theory [18-21]. Hong et al. [22] made a comparison among some of

56 these advanced models, and showed that the multiple plastic hardening mechanism

57 were of paramount importance in modeling complex thermal loading behavior.

58 Though numerous efforts were made in thermal mechanical modeling, most existing

59 models can only simulate the case of one thermal cycle and fail in describing the soil

60 behavior under multiple heating-cooling cycles. As more attention has been paid to the

61 long-term performance $[11,12,25,26,27,40]$, the volume change and excess pore water

62 pressure accumulation due to temperature variation can act as a significant factor

63 influencing the safety of energy structures. Demars and Charles [23] reported a series 
64 of drained thermal cycle tests on high plastic marine clays and found that permanent reduction in void ratio (a function of over-consolidation ratio) gradually reduced due to temperature cycles (see Fig.1). Plum et al. [24] conducted an undrained heating-cooling cycle tests on Newfield clay. After four thermal cycles, the accumulation of excess pore water pressure was still increasing. Pastén et al. [40] experimentally observed the thermally driven displacement accumulation with the number of temperature cycles and developed a thermally induced ratcheting mechanism for a smooth interface. All those

71 observations show that multiple thermal cycles should be considered in thermal mechanical modeling of clays. Zhou et al. [28] recently proposed a bounding surface model with a memory surface to consider the thermal cyclic behavior. However, this imposed memory surface actually has no effect on the accumulation behavior of normally consolidated soil because this memory surface coincides with the bounding surface in this circumstance. Ma et al. [29] proposed a thermal stabilization line in hypoplastic modeling approach. Though three thermal parameters are introduced, the proposed hypoplastic model fails to describe the strain accumulation during relatively small temperature changes because it always simulates an unrealistic elastic behavior

80 before entering the elasto-plastic zone following a thermal loading path. More recently,

81 Zymnis et al. [41] proposed a simple calibration procedure for Tsinghua ThermoSoil

82 (TTS) model and studied the capabilities of simulating the long-term accumulation of 83 strains due to thermal cycles. However, those existing models for thermal cyclic behavior merely considered the strain accumulation behavior under drained conditions 
though the excess pore water pressure buildup due to temperature effects are at least of equal importance from the best of the authors' knowledge.

In the present work, a two surface thermo-plastic model, namely ACC2-T, is proposed to consider the thermal cyclic behavior based on the previous TEAM model by Hong et al. [21]. The proposed model unifies the loading yield limits and the thermal yield limits. To connect the inner loading yield limit and the loading yield limit, a flexible dependency law is incorporated and combined with isotropic and progressive hardening laws to account for multiple thermal cycles. In the dependency law, a parameter $n_{c}$ is introduced to control accumulation rate through the evolution rate of the inner loading yield limit approaching the loading yield limit. Meanwhile, the proposed model is extended to undrained condition by applying the thermo-hydro-mechanical equations by Coussy [30] into the elastic-plastic state. Then, the rationale of ACC2-T model is discussed in terms of elasto-plasticity and thermodynamic theories. Lastly, the thermal cycle test results of four fine-grained soils (natural Boom clay, Geneva clay, Bonny silt and reconstituted Pontida clay) under different OCRs and stresses are used to verify the proposed model.

\section{Model description}

In this section, the proposed model (ACC2-T) is presented using typical constitutive variables, namely mean effective stress $p^{\prime}$, deviator stress $q$, temperature $T$ and the corresponding increments $\left(d p^{\prime}, d q, d T\right)$. The soil behavior is assumed to be isotropic 
106

107 108 111 plastic parts.

112

113

114

115

116

118

\subsection{Thermo-plastic behavior}

125 conditions.

\subsection{Thermo-elastic behavior} modulus and $v$ is the Poisson's ratio.

and the constitutive model is developed and formulated in the conventional triaxial

In ACC2-T model, the soil deformation can be divided into thermo-elastic and thermo-

In the thermo-elastic part, the elastic law adopted in many other models [31,36,37] in isothermal conditions are extended into non-isothermal conditions for its simplicity. the total elastic volumetric strain increment associated with mechanical and thermal loading and the elastic shear strain assumed purely mechanical are calculated as follows:

$$
d \varepsilon_{v}^{e}=\frac{\kappa d p^{\prime}}{v p^{\prime}}-\alpha_{1} d T, d \varepsilon_{s}^{e}=\frac{d q}{3 G}, G=\frac{3(1-2 v)}{2(1+v)} \frac{v p^{\prime}}{\kappa}
$$

where $d \varepsilon_{v}^{e}, d \varepsilon_{s}^{e}$ is the elastic volumetric strain increment $\left(d \varepsilon_{v}^{e}=d \varepsilon_{1}^{e}+d \varepsilon_{2}^{e}+d \varepsilon_{3}^{e}\right)$ and the elastic shear strain increment $\left(d \varepsilon_{s}^{e}=\frac{2}{3}\left(d \varepsilon_{1}^{e}-d \varepsilon_{3}^{e}\right)\right) . \kappa$ is the elastic slope in $(v$, $\ln p^{\prime}$ ) plane and $v$ is the specific volume. $\alpha$ is the thermal elastic compressibility index which assumed a positive constant because heating induces soil expansion. $G$ is shear

The thermo-plastic mechanism of ACC2-T model consists of two yield surfaces and plastic potential surface, the dependency law, the isotropic and progressive hardening 
laws and the flow rules.

In ACC2-T model, two yield surfaces, namely loading surface $\left(f_{I}\right)$ and yield surface $\left(f_{Y}\right)$,

130 with a generalized formulation [31] are implemented to model the yielding of both stiff

131 and soft clays.

132 Loading Surface: $f_{I}=q^{2}+\frac{M_{f}^{2}}{1-k_{f}}\left(\frac{p^{\prime}}{r \bar{p}_{c T}^{\prime}}\right)^{\frac{2}{k_{f}}}\left(r \bar{p}_{c T}^{\prime}\right)^{2}-\frac{M_{f}^{2} p^{\prime 2}}{1-k_{f}}=0$

133 Yield Surface: $f_{Y}=q^{2}+\frac{M_{f}^{2}}{1-k_{f}}\left(\frac{p^{\prime}}{\bar{p}_{c T}^{\prime}}\right)^{\frac{2}{k_{f}}} \bar{p}_{c T}^{\prime 2}-\frac{M_{f}^{2} p^{\prime 2}}{1-k_{f}}=0$

134 where $M_{f}$ is the stress ratio at the apex of two surfaces, $k_{f}$ is a parameter specifying the 135 shape of yield surfaces, $\bar{p}_{c T}^{\prime}$ is the pre-consolidation pressure at current temperature $T$

137 conceptual plot of two yield surfaces at various temperature is given in Fig. 2(a). To consider the thermo-mechanical behavior, the two surfaces are extended into three-

139 dimensional plot $\left(p^{\prime}, q, T\right)$ with two loading yield limits. The two loading yield limits, namely the inner loading yield limit (ILY) and the loading yield limit (LY) are linked by

141 the proposed dependency law which is discussed in Yield limits and dependency law 142 section.

143 The plastic potential surface $\mathrm{g}_{I}$ takes the same form as for loading surface, but with 144 different parameters $M_{g}$ and $k_{g}$ : 
$g_{I}=q^{2}+\frac{M_{g}^{2}}{1-k_{g}}\left(\frac{p^{\prime}}{r \beta}\right)^{\frac{2}{k_{g}}}(r \beta)^{2}-\frac{M_{g}^{2} p^{\prime 2}}{1-k_{g}}=0$

146 and it leads to a dilatancy equation in the case of triaxial compression:

$147 \frac{d \varepsilon_{v}^{p}}{d \varepsilon_{s}^{p}}=\frac{\frac{\partial g_{I}}{\partial p^{\prime}}}{\frac{\partial g_{I}}{\partial q}}=\frac{M_{g}^{2}-\eta^{2}}{k_{g} \eta}$

148 where $d \varepsilon_{v}^{p}$ is the plastic volumetric strain increment, $d \varepsilon_{s}^{p}$ is the plastic shear strain

149 increment, $\eta$ denotes the stress ratio $q / p^{\prime}, M_{g}$ defines the critical stress ratio at failure

150 where no further volumetric strain increment develops, $k_{g}$ is a constant parameter which

151 controls the ratio of plastic volumetric strain increment and plastic shear strain

152 increment and $\beta$ is the size parameter. Typically, an unassociated flow rule is adopted

153 for modeling complex mechanical behaviors. However, when $M_{g}=M_{f}$ and $k_{g}=k_{f}$, an

154 associated flow rule would be recovered. When $k_{g}=k_{f}=2$, elliptical surfaces like

155 modified Cam-clay model are recovered.

156

157 2.2.2 Hardening laws

158 In ACC2-T model, two plastic hardening mechanisms fixed to reference temperature

$159 T_{0}$ are adopted to control the evolution of yield surface and loading surface.

160 In the isotropic hardening rule, as same as in Modified Cam-clay model, the

161 evolution of pre-consolidation pressure $\bar{p}_{c 0}^{\prime}$ at reference temperature $T_{0}$ is linked to the

162 plastic volumetric strain increment:

$163 d \bar{p}_{c 0}^{\prime}=\frac{v}{\lambda-\kappa} \bar{p}_{c 0}^{\prime} d \varepsilon_{v}^{p}$ 
164 where $\lambda$ is the normal consolidation slope in $\left(v, \ln \mathrm{p}^{\prime}\right)$ plane and $d \bar{p}_{c 0}^{\prime}$ is the increment

165 of pre-consolidation pressure. It means the evolution of yield surface is dominated by 166 the plastic volumetric strain.

167 The progressive hardening variable $d r_{0}$, at reference temperature $T_{0}$, is defined with 168 a combined volumetric and shear plastic strain as follows:

$169 \quad d r_{0}=\frac{v}{\lambda-\kappa} S\left(1-r_{0}\right)\left(d \varepsilon_{v}^{p}+A_{d} d \varepsilon_{s}^{p}\right)$

170 where $r_{0}$ is the inverse of over-consolidation ratio (OCR) at current temperature $T_{0}$ and

$171 d r_{0}$ is the increment. $s$ is a material constant which controls the hardening rate of loading

172 surface in approaching yield surface. $A_{d}$ is a material constant which controls the 173 contribution of shear plastic strain.

174 In this progressive hardening rule, parameter $r_{0}$ is always less than or equal to $1(0<$

$\left.175 r_{0} \leq 1\right)$. When the loading surface is completely inside the yield surface $\left(0<r_{0}<1\right)$, it

176 means the soil is over-consolidated. Within the hardening process, plastic strain

177 increases and the loading surface begins to move towards the yield surface $\left(d r_{0}>0\right)$.

178 When $r_{0}=1$, the loading surface and the yield surface coincide. The soil turns into

179 normally consolidated state as the same case of MCC model. Note that the loading

180 surface could not run out of the yield surface $\left(r_{0}>1\right)$ for the fact that if $r_{0}>1, d r_{0}<0$

181 holds. With such a combined volumetric-deviatoric hardening law, the inclusion of

182 shear hardening part $\left(d \varepsilon_{s}^{p}>0\right)$ would lead to a positive plastic modulus $(h>0)$ even

183 when the effective stress state $\left(d \varepsilon_{v}^{p}=0\right)$ reach the critical state line (CSL). As a

184 consequence, the stress point lying on the loading surface can cross the CSL, 
185

186

187

188

189 With these isotropic and progressive hardening rules, the plastic modulus and

190

191 Under loading and heating processes, two hardening variables $\bar{p}_{c 0}^{\prime}$ and $r_{0}$ are

192 activated with the evolution of plastic strain. However, under unloading and cooling

193 processes, pure elastic strain develops with a fixed value of $\bar{p}_{c 0}^{\prime}$. Due to ACC2-T model

194 strictly adhering to the principle that the stress point is always lying on the loading

195 surface, the value of $r_{0}$ could be re-calculated by a simple Newton-Raphson Method

196 with unconditional stability.

198 2.2.3 Yield limits and dependency law

199 In the two surface models, the loading surface and the yield surface are geometrically

200 similar in $\left(p^{\prime}, q\right)$ plane with a corresponding radial mapping rule. In previous TEAM

201 model [21], two yield limit mechanisms, namely thermal yield limits (ITY, TY) and

202 loading yield limits $(I L Y, L Y)$ are adopted to model the thermal behavior. These yield

203 limit mechanisms in TEAM model (see Fig.3(a)) enable the thermal elastic response in

204 reloading path to occur before entering the elasto-plastic zone. Therefore, the TEAM

205 model could not simulate the strain accumulation phenomenon due to temperature 
variations. In order to overcome this shortcoming and extend the model to the case of

207 multiple thermal cycles, the loading yield limits $(I L Y, L Y)$ are unified to consider both

208 the thermal yield and loading yield mechanisms. Meanwhile, a new dependency law is

209 proposed to connect $I L Y$ and $L Y$.

210 In the dependency law, the pre-consolidation pressure $\bar{p}_{c T}^{\prime}$ at current temperature $T$

211 takes the original form and it would decrease with the increase of temperature:

$212 \quad \bar{p}_{c T}^{\prime}=\bar{p}_{c 0}^{\prime} \exp \left[-\alpha_{0}\left(\mathrm{~T}-\mathrm{T}_{0}\right)\right]$

213 where $\bar{p}_{c 0}^{\prime}$ is pre-consolidation pressure at reference temperature $T_{0} ; \alpha_{0}$ is a material

214 constant controlling the thermal plastic behavior.

215 The other part of the dependency law $r$ is defined as below:

$216 \quad r=\frac{1}{O C R}=\frac{p^{\prime}}{\bar{p}^{\prime}}=\frac{q}{\bar{q}}=\frac{p_{c T}^{\prime}}{\bar{p}_{c T}^{\prime}}$

217 where $\left(p^{\prime}, q\right),\left(\bar{p}^{\prime}, \bar{q}\right)$ is the corresponding stress point in loading surface and yield

218 surface at current temperature $T$, respectively.

219 Unlike TEAM model with the assumption that $r=r_{0}$, ACC2-T model takes the form

220 that would make $I L Y$ not necessarily homologous to $L Y$ any longer (see Fig.3(b)):

$221 r=r_{0} \exp \left[-\alpha_{0}\left(r_{0}^{n_{c}}-1\right)\left(\mathrm{T}-\mathrm{T}_{0}\right)\right]$

222 where $n_{c}$ is a thermal parameter which controls the strain accumulation rate under 223 multiple thermal cycles.

224 The combined dependency law made up by $\bar{p}_{c T}^{\prime}$ and $r$ then is expressed by:

$225 \quad r \bar{p}_{c T}^{\prime}=r_{0} \bar{p}_{c 0}^{\prime} \exp \left[-\alpha_{0} r_{0}^{n_{c}}\left(\mathrm{~T}-\mathrm{T}_{0}\right)\right]$

226 In the proposed law, the shape of ILY is governed by the key thermal accumulation 
228 isotropic and progressive hardening rules. In order to illustrate the plastic mechanism

229 under the thermal path, two cases in the isotropic states, namely $n_{c}<0$ and $n_{c}=0$, are

230 compared in Fig.4. Both two cases are at initial stress state A, then heated up to stress

231 state B and finally cooled down to stress state A. Under the heating path from A to B, 232 the $I L Y$ without $n_{c}\left(n_{c}=0\right)$ would induce a increment of $\Delta r_{1}$. For the case of $n_{c}<0$, it 233 would induce a increment of $\Delta r_{1}+\Delta r_{2}+\Delta r_{3}$ if the shape of ILY is fixed. However, with 234 the effect of $n_{c}$, the original $I L Y$ (see Fig.4(b), dotted line I) would gradually turn into 235 solid line II with a actual increment of $\Delta r_{1}+\Delta r_{2}$. The larger increment $\Delta r_{1}+\Delta r_{2}$ in 236 hardening variable $d r 0$ would mean larger plastic volumetric strain increments than the 237 case of $n_{c}=0$. Under the cooling path from B to A, the mechanical response is purely 238 elastic and the shape of $I L Y$ would turn from II into I. For the case of $n_{c}>0$, the 239 increment in hardening variable $d r_{0}$ would induce smaller strain increments than $n_{c}=0$.

240 Under multiple thermal cycles, the value of $r_{0}$ would be smaller and smaller.

241 Under such a unique dependency law, the evolution rate of $I L Y$ is actually the 242 evolution rate of strain accumulation. With a proper selection of parameter $n_{c}$ in the 243 dependency law, ACC2-T model allows the strain accumulation under the effect of 244 multiple thermal cycles to be modelled. Some important features about the dependency 245 law and parameter $n_{c}$ are summarized below:

246 1. When the current temperature $T$ is equal to the reference temperature $T_{0}, r$ becomes 247 equal to $r_{0}$. It means that $n_{c}$ would have no effect on the stress-strain relationship at 
reference temperature $T_{0}$.

249 2. When soil turns into the normal consolidated state $\left(r_{0}=1\right), r$ is also equal to 1 . In that 250 case, $I L Y$ would coincide with $L Y$. It means that $n_{c}$ would have no effect on the behavior 251 of normal consolidated soils under either isothermal or non-isothermal condition.

252 3. When $n_{c}$ is equal to zero (bold line in Fig. 3(b)), $r$ becomes equal to $r 0$. In that case, 253 a similarity between $I L Y$ and $L Y$ would be recovered. This is just the case of $I L Y$ and $L Y$ 254 used in TEAM model [21].

2554 . Theoretically, the value of $n_{c}$ can be chosen from negative infinity to positive infinity. 256 When $n_{c}$ tends to positive infinity, $I L Y$ would tend to be the dotted line in Fig. 3(b). 257 When $n_{c}$ tends to negative infinity, $I L Y$ would tend to approach the temperature axis $T$ 258 in Fig. 3(b). A larger $n_{c}$ represents a quicker strain accumulation rate which would 259 induce smaller total volumetric strain accumulation under the effect of thermal cycles. 260 5. Any possible $r$ is smaller than 1. During the heating process, the hardening implies that the over-consolidation ratio of soil is always larger than or equal to 1 .

\section{Loading path independence}

After the description of the proposed model extended to thermal cyclic behavior, it is essential to discuss the rationale of ACC2-T model in terms of elasto-plastic theory and thermodynamic theory as Hong et al. [22] did on three existing thermo-mechanical models $[19,20,25,28,29]$. The verification of loading path independence is made up by 
both the thermo-elastic and thermo-plastic part. The schematic plot is given in Fig.5.

270 Heating is treated as a special isotropic loading. Therefore, merely isotropic condition $271(q=0)$ is considered during the derivation. The thermo-elastic part is discussed as 272 below and the derivation in thermo-plastic regime is attached in Appendix B.

273 In the thermo-elastic mechanism (Eq.3) of ACC2-T model, the bulk modulus

$274 K=\frac{v p^{\prime}}{\kappa}$ is independent of temperature, and thermal elastic compressibility index $\alpha_{1}$ 275 is also independent of mean effective stress. Such elastic volumetric strain in ACC2-T 276 model is surely loading path independent in $\left(p^{\prime}, T\right)$ plane. Note that the thermo-elastic 277 mechanism leads to loading path dependent in $\left(p^{\prime}, q\right)$ plane since the Maxwell symmetry 278 relations are not satisfied. A possible way is to extend a hyperelastic law [39] into non279 isothermal conditions. For simplicity of parameter calibration, merely this thermo280 elastic mechanism is considered here.

\section{Analysis and determination of model parameters}

The proposed ACC2-T model contain fifteen parameters $\left(\lambda, \kappa, \bar{p}_{c 0}^{\prime}, v, M_{f}, k_{f}, M_{g}, k_{g}, s\right.$, $\left.r_{0}, A_{d}, \alpha_{0}, \alpha_{1}, T_{0}, n_{c}\right)$. Five of them $\left(\lambda, \kappa, \bar{p}_{c 0}^{\prime}, v, M_{g}\right)$ are commonly defined in MCC model. $\left(M_{f}, k_{f}\right),\left(M_{g}, k_{g}\right)$ control the shapes of yield surfaces and plastic potential surfaces, respectively. Three parameters $\left(s, r_{0}, A_{d}\right)$ are used to consider a progressive

287 yielding of two surfaces. Four parameters $\left(\alpha_{0}, \alpha_{1}, T_{0}, n_{c}\right)$ are defined to consider the thermal influence on the soil behavior. The procedure for determining these parameters is described and key parameters $\left(\lambda, \kappa, \bar{p}_{c 0}^{\prime}, s, r_{0}, \alpha_{0}, \alpha_{1}, T_{0}, n_{c}\right)$ related to thermal 
accumulation behavior are discussed on the set of model parameters for natural Boom

291 clay in Fig. 6.

292 1. By an isotropic compression test or oedometer test under reference temperature $T_{0}$, $293 \kappa, \lambda$, the initial $r_{0,0}$ and $\bar{p}_{c 0,0}^{\prime}$ are determined in $\left(v, \ln p^{\prime}\right)$ plane in Fig.6(1). Note that 294 parameter $s$ controls the hardening rate of loading surface in approaching yield surface. 295 It can be determined by fitting nonlinearity from over-consolidated states to normal 296 consolidated state in $\left(v, \ln p^{\prime}\right)$ plane.

2. By an isotropic heating-cooling test at normally consolidated states, $\alpha_{1}$ is 298 determined by fitting data of cooling stage and $\alpha_{0}$ is determined by the heating test in $299\left(T, \Delta \varepsilon_{v}\right)$ plane in Fig.6(2).

3. By a continuous thermal cycle test, the volumetric strain increment by each thermal cycle $\Delta \varepsilon_{v, s t}$ can be obtained $\left(\Delta \varepsilon_{v, s t}, n\right)$ plane in Fig.6(3). The thermal accumulation parameter $n_{c}$, which controls the strain accumulation rate, is then determined by calibrating the strain accumulation under each thermal cycle.

4. $M_{f}, k_{f} . M_{f}$ denotes the apex of yield surface and $k_{f}$ controls the shape of yield surface. They are calibrated by fitting the converntional yield points of various stress paths.

5. $M_{g}$ is the critical state stress ratio and it is calibrated by the effective stress ratio at critical state.

308 6. $k_{g}$ controls plastic flow direction. It is determined by fitting the values of $d \varepsilon_{v}^{p} / d \varepsilon_{s}^{p}$ 309 in drained triaxial shear tests.

3107 . The poisson's ratio $v$ is determined by a triaxial tests at low strain level in the $\left(\varepsilon_{v}-\varepsilon_{1}\right)$ 
311 plane: $\nu=\left(\varepsilon_{v}-\varepsilon_{1}\right) / 2$.

$3128 . A_{d}$ represents the contribution of the plastic shear strain in the hardening process. It

313 is calibrated by fitting the results of triaxial compression tests at over-consolidated

314 states in $\left(q, \varepsilon_{l}\right)$ or $\left(\varepsilon_{v}, \varepsilon_{l}\right)$ plane in Fig.6(4).

315

316 5. Model Validation and prediction

317 In this section, four different fine-grained soils, namely natural Boom clay, Geneva clay,

318 Bonny silt and reconstituted Pontida clay, are adopted to verify the capability of ACC2-

319 T model in modeling the thermal cyclic behavior.

\subsection{Natural Boom clay}

322 One heating and cooling test on natural Boom clay $\left(I_{p}=31\right)$ under isotropic stress

323 states performed by Baldi et al. [8] and two groups of triaxial compression tests 324 conducted by Lê [38] are taken into account.

325 In the heating and cooling test, specimen TBoom-9 taken from Mol at an in-situ depth 326 of $223 \mathrm{~m}$ (initial pre-consolidated pressure of $6 \mathrm{MPa}$ ) is tested under a mixed 327 mechanical and thermal loading process: the sample was firstly saturated under a 328 constant mean effective stress of $2 \mathrm{MPa}$ at $21.5^{\circ} \mathrm{C}$, loaded up to $4 \mathrm{MPa}$, unloaded to 1

$329 \mathrm{MPa}$, heated up to $95^{\circ} \mathrm{C}$ and cooled back to $21.5^{\circ} \mathrm{C}$, loaded up to $3 \mathrm{MPa}$ at $21.5^{\circ} \mathrm{C}$ 330 and heated up to $95^{\circ} \mathrm{C}$ and cooled back, loaded up to $6 \mathrm{MPa}$ and heated up again and 331 finally cooled back. In the loading process, three thermal cycles of temperature 
increment of $73.5^{\circ} \mathrm{C}$ at different isotropic stress states, namely mean effective stress of

$3331 \mathrm{MPa}, 3 \mathrm{MPa}$ and $6 \mathrm{MPa}$, are selected for simulation. For better comparison between

334 the computed and measured results, the increments of volumetric strain are reset at the

335 starting point of each heating-cooling cycle. Moreover, Fig. 7 contains an isotropic

336 compression test of natural Boom clay from $2 \mathrm{MPa}$ to $20 \mathrm{MPa}$, then back to $6 \mathrm{MPa}$.

337 Basic parameters for natural Boom clay are listed in Tab.1.

338 The TEAM model [21] and the proposed ACC2-T model are both used for simulation

339 in Fig.8. It appears that both models can describe the thermal volume change well for

340 normally consolidated or slightly over-consolidated state $\left(p^{\prime}=6 \mathrm{MPa}\right)$ adopting the

341 same thermal elastic parameter $\alpha_{1}$ and thermal plastic parameter $\alpha_{0}$. However, for

342 highly over-consolidated states $\left(p^{\prime}=3 \mathrm{MPa}, p^{\prime}=1 \mathrm{MPa}\right)$, it is observed that ACC2-T

343 model gives a more consistent simulation than TEAM model. One reason is that TEAM

344 model always shows a linear elastic expansion behavior before entering the elasto-

345 plastic zone and has no parameters controlling strain evolution. With this shortcoming,

346 TEAM model would fail to respond to thermal cycles and thus to describe strain

347 accumulation behavior, though complicated multiple plastic mechanisms are adopted.

348 However, in ACC2-T model, the stress point is always lying on the loading surface.

349 Combined with the isotropic and progressive hardening rules, the thermal accumulation

350 parameter $n_{c}$ in the dependency law allows the ACC2-T model to better describe the

351 nonlinear expansion behavior and strain accumulation under over-consolidated states.

352 Meanwhile, as natural Boom clay is relatively easy to contract under heating, the use 
353 of a negative value of parameter $n_{c}$ could facilitate the simulation of such aspect.

354 In the triaxial compression test, the experimental results of drained triaxial

355 compression tests $\left(p_{0}^{\prime}=2.5 \mathrm{MPa}, p_{0}^{\prime}=4 \mathrm{MPa}\right)$ at room temperature $25^{\circ} \mathrm{C}$ and drained

356 triaxial compression tests $\left(p_{0}^{\prime}=2.5 \mathrm{MPa}, p_{0}^{\prime}=3.8 \mathrm{MPa}\right)$ at high temperature $76^{\circ} \mathrm{C}$

357 [38] are considered in $\left(q, \varepsilon_{1}\right)$ plane and $\left(\varepsilon_{v}, \varepsilon_{1}\right)$ plane in Fig.9. In these moderate over-

358 consolidated states, the shear strength at room temperature is a bit higher than high

359 temperture. However, a larger volumetric strain is generated at high temperature than

360 room temperature as shown in $\left(\varepsilon_{v}, \varepsilon_{1}\right)$ plane. At the same time, the smooth predictions

361 by ACC2-T model agree well with the experimental observations. Two values of $n_{c}\left(n_{c}\right.$

$\left.362=-1, n_{c}=0\right)$ are selected to simulate the behaivor at high temperature $76^{\circ} \mathrm{C}$. It indicates

363 that the value of $n_{c}$ has a negligible effect on the prediction of triaxial tests.

364 A numerical case at high over-consolidated state $\left(p_{0}^{\prime}=0.5 \mathrm{MPa}\right)$ under both two

365 temperatures $\left(25^{\circ} \mathrm{C}, 76^{\circ} \mathrm{C}\right)$ are conducted. A slight shear dilatancy is predicted at axial

366 strain of about 5\%. However, the post-peak softening phenomenon in $(q-\varepsilon 1)$ plane is not

367 very apparent because parameter $A_{d}\left(A_{d}=0.1\right)$ for natural Boom clay is very small to

368 simulate behaviors at both high, slightly over-consolidated and normal consolidated

369 states.

\subsection{Geneva clay}

372 Multiple thermal cycles were applied on Geneva clays $\left(I_{p}=11.1\right)$ in a temperature-

373 controlled oedometer cell under drained condition [25]. A normally consolidated soil 
374 sample with a vertical effective stress of $125 \mathrm{kPa}$ was tested with four temperature 375 cycles from $5{ }^{\circ} \mathrm{C}$ from $60^{\circ} \mathrm{C}$, starting at a room temperature of $20^{\circ} \mathrm{C}$. The one376 dimension test results are simulated in Fig.7 and the calibrated model parameters are 377 listed in Tab.1.

378 Fig.10 shows the measured and computed soil behavior under multiple heating and 379 cooling cycles. The computed result of ACC2-T model (Fig.10(a)) shows a good 380 agreement with the measured one. The irreversible volumetric strain accumulates with 381 increasing thermal cycles, but at a decreasing rate (Fig.10(c)). The value of 3.5 is shown 382 appropriate for the thermal accumulation parameter $n_{c}$ to control the strain 383 accumulation rate. For the case of TEAM model, the computed result of first thermal 384 cycle is the same as ACC2-T model. However, the response of TEAM model is purely 385 elastic thereafter and the thermal strain accumulation could not be described. In 386 Fig.10(b), a sensitivity analysis of ACC2-T model is conducted to study the effect of 387 parameter $n_{c}$ on the strain accumulation. Two other $n_{c}$ values of 0,10 are selected for 388 this purpose. In the first thermal cycle, ACC2-T model gives the same results for all the 389 three $n_{c}$ values because the thermal volumetric strain of normally consolidated soil is 390 only dependent on thermal elastic parameter $\alpha_{1}$ and thermal plastic parameter $\alpha_{0}$.

391 From the second thermal cycle, the soil becomes over-consolidated. The thermal 392 accumulation parameter $n_{c}$ starts to control the strain evolution rate. From Fig.10(c), it 393 appears that parameter $n_{c}$ is positively correlated to the strain accumulation rate and a 394 proper selection of parameter $n_{c}$ is crucial for total strain accumulation. 
411 simulation.

\subsection{Bonny silt}

Multiple heating and cooling cycles were applied on compacted Bonny silt $\left(I_{p}=4\right)$ under different OCRs in a temperature-controlled oedometer cell [27]. Bonny silts were first mechanically consolidated to a vertical effective stress of approximately $1200 \mathrm{kPa}$ at a constant room temperature of $18^{\circ} \mathrm{C}$. Then, they were unloaded to reach five different OCR values of $1.00,1.28,1.80,7.36$ and 30.29. Fig. 7 presents the experimental and calibration results of one-dimensional test of Bonny silt. Four heating and cooling cycles were applied under drained condition with different OCRs in a temperature ranging from $18{ }^{\circ} \mathrm{C}$ to $93{ }^{\circ} \mathrm{C}$.

It can be seen from Fig.11 that at slightly over-consolidated states (i.e. OCR = 1, 1.28 and 1.8), the measured and computed results show a good consistency. That means the thermal accumulation parameter $n_{c}$ can properly control the strain evolution rate under various over-consolidated states. However, for highly over-consolidated ones (i.e. OCR $=7.36,30.29)$ in the literature [27], the volumetric strain accumulation is quite small or even becomes negative, suggesting that the expansion and the contraction of the oedometer cell can be no longer ignored. These two samples are not considered in the

\subsection{Reconstituted Pontida clay}

414 The excess pore water pressure accumulation due to thermal cycles in validated by a 415 heating and cooling test of reconstituted Pontinda clay. Hueckel et al [12] reported this 416 measured and computed results on reconstituted Pontida clay. The reconstituted silty 
417 clay sample was firstly loaded to a mean effective stress state of $2.5 \mathrm{MPa}$. Then it 418 underwent a heating-cooling cycle from $22^{\circ} \mathrm{C}$ to $65^{\circ} \mathrm{C}$ and back to $22^{\circ} \mathrm{C}$, then a 419 continuous heating to $95^{\circ} \mathrm{C}$ in a constant total isotropic stress state.

420 Although some previous models [19] consider the undrained behavior by imposing 421 a constant volume condition which is imprecise under non-isothermal conditions, the undrained computation using ACC2-T model is obtained by extending the energy and mass conservation of thermo-poro-elastic media into elasto-plastic states [30].

In a saturated porous media, the current water mass $\left(m_{\mathrm{w}}\right)$ per unit volume can be 425 expressed as:

$m_{w}=\rho_{w} \phi$

where $\rho_{w}$ is water density and $\phi$ is the Lagrangian porosity.

In undrained conditions, water mass is constant and $d m_{w}=0$ holds, then

$$
\frac{d m_{w}}{\rho_{w}}=d \phi+\phi \frac{d \rho_{w}}{\rho_{w}}=d \phi+\phi\left(C_{w} d u-\alpha_{w} d T\right)=0
$$

where $\alpha_{w}, C_{w}$, is the water thermal expansion coefficient, water compressibility, respectively.

In isotropic stress state and under non-isothermal condition, total mean stress change $(d p)$ and Lagrangian porosity change $(d \phi)$ can be expressed with Maxwell's symmetry condition:

$$
d p=\frac{1}{C_{d}} d \varepsilon_{v}+\left(1-\frac{C_{s}}{C_{d}}\right) d u_{w}+\frac{\alpha_{d}}{C_{d}} d T
$$

$$
d \phi=-\left(1-\frac{C_{s}}{C_{d}}\right) d \varepsilon_{v}-\left(\phi-1+\frac{C_{s}}{C_{d}}\right) C_{s} d u_{w}+\left(\phi-1+\frac{C_{s}}{C_{d}}\right) \alpha_{s} d T
$$

where $C_{s}, C_{d}, \alpha_{s}, \alpha_{d}$ is the volumetric compressibility coefficient of solid grain, the volumetric compressibility of soil skeleton, the thermal expansion coefficient of solid grain and the thermal expansion coefficient of soil skeleton. It is often the case that $\alpha_{s}$ $440=\alpha_{d}$.

441 Thus, the expressions for excess pore water pressure can be obtained, as follows: 
$d \varepsilon_{v}=-\left(\phi \alpha_{w}+(1-\phi) \alpha_{s}\right) d T+\phi\left(C_{w}-C_{s}\right) d u_{w}+C_{s} d p$

With infinitesimal transformation and clayey soils, the fact $\left(C_{s} \approx 0, n \approx \phi\right)$ is commonly accepted. Thus

$d u_{w}=\frac{d \varepsilon_{v}+\left(n \alpha_{w}+(1-n) \alpha_{s}\right) d T}{n C_{w}}$

where $n$ is Eulerian porosity.

For reconstituted Pontida clay, $\alpha_{s}$ is $1 \times 10^{-5}\left(1 /{ }^{\circ} \mathrm{C}\right)$ chosen as same as $\alpha_{1}$, which is calibrated from an undrained cooling process from $65^{\circ} \mathrm{C}$ to $22^{\circ} \mathrm{C} . \alpha_{w}$ and $C_{w}$ are calibrated from a heating test of free water in the literature [35].

The computed results of excess pore water pressure by ACC2-T model and TEAM model are compared to the measured data and Hueckel's simulation [12] in Fig.12. It is seen that both predictions of ACC2-T model and TEAM model are more accurate than Hueckel's simulation, especially the existed buildup of pore water pressure in experimental results. During the heating stage from $22^{\circ} \mathrm{C}$ to $65^{\circ} \mathrm{C}$, the mean effective stress will decrease with temperature (equivalent to a mechanical loading under undrained condition) and the effective stress-temperature path $\left(T-p^{\prime}\right)$ initially enters plasticity. With the plastic hardening of $I L Y$, excess pore water pressure is increased. Then during the cooling stage from $65^{\circ} \mathrm{C}$ to $22^{\circ} \mathrm{C}$, the response is purely elastic with a decrease of the pore water pressure. Thereby, an irreversible excess pore water pressure is observed after one heating-cooling cycle which is well captured by ACC2-T model and TEAM model. Moreover, though the cooling stage is purely elastic, the ILY would

463 heating process, TEAM model could not build up excess pore water pressure from $22^{\circ} \mathrm{C}$ 464 to $65^{\circ} \mathrm{C}$ because the response is purely elastic. As for ACC2-T model, the clay sample 465 is initially over-consolidated, then began to build up excess pore water pressure with 466 the control of thermal accumulation parameter $n_{c}$ in the whole process from $22^{\circ} \mathrm{C}$ to $46795^{\circ} \mathrm{C}$. 


\subsection{Discussion}

Four fine-grained soils are selected to verify the capability of ACC2-T model on modelling thermal cyclic behaviors under drained and undrained conditions. A thermal accumulation parameter $n_{c}$ control the accumulation rate under multiple thermal cycles.

472 Meanwhile, the values of $n_{c}$ are ranked as: natural Boom clay $<$ reconstituted Pontida

473 clay $<$ Geneva clay $<$ Bonny silt. It means the clays, containing more clay contents, 474 showing larger plastic index $I_{p}$, are more likely to accumulate volumatric strain and 475 build up excess pore water pressure. Generally, the larger is the plastic index $I_{p}$, the 476 smaller is the value of $n_{c}$. A liner regression function is obtained to evaluate the 477 correlation between parameter $n_{c}$ and plastic index $I_{p}$ in Fig. 13.

\section{Concluding remarks}

480 A two-surface plasticity model (ACC2-T) is proposed to describe the thermo-

481 mechanical behavior of fine-grained soils under multiple thermal cycles. Compared 482 with TEAM model, two thermal yield limits are removed and the loading yield limits 483 unify the thermal and loading yielding part. A dependency law with thermal 484 accumulation parameter $n_{c}$ is used to link the inner loading yield limit and the loading 485 yield limit. Parameter $n_{c}$ controls the evolution rate of the inner loading yield limit 486 approaching the loading yield limit under thermal loading path. With such a unique 487 dependency law and multiple plastic hardening rules, the model could well control the 488 thermal strain accumulation rate under drained conditions and pore water pressure 
489 buildup rate under undrained conditions. Tests on four fine-grained soils are considered 490 to verify the proposed model. Comparison between prediction and experiment shows 491 that ACC2-T model can well capture the thermo-mechanical behavior of soils under 492 multiple thermal cycles.

\section{Acknowledgements}

496 The present work is carried out with the support of National Natural Science Foundation of China $(51608188,758201011)$. The authors also wish to acknowledge the support of

498 the European Commission by the Marie Skłodowska-Curie Actions HERCULES499 Towards Geohazards Resilient Infrastructure Under Changing Climates (H2020500 MSCA-RISE-2017, 778360) 
$511 \quad \alpha_{0}=$ parameter controlling thermal plastic behavior;

$512 \quad \alpha_{1}=$ parameter controlling thermal elastic behavior;

$513 \beta=$ the size parameter of potential plastic surface;

$514 \lambda, \kappa=$ slope of isotropic loading, reloading line respectively;

$515 v, v=$ current void ratio, Poisson's ratio respectively;

$516 A_{d}=$ parameter controlling the contribution of shear plastic strain;

$517 d \boldsymbol{\varepsilon}, d \boldsymbol{\sigma}, d T=$ total strain, stress, temperature increment respectively;

$518 d \boldsymbol{\varepsilon}_{\sigma}^{e}, d \boldsymbol{\varepsilon}_{T}^{e}=$ stress, thermal induced elastic strain increment respectively;

$519 d \varepsilon_{v}, d \varepsilon_{v}^{e}, d \varepsilon_{s}^{e}=$ total volumetric, elastic volumetric, shear strain increment

520 respectively;

$521 d \boldsymbol{\varepsilon}^{p}, d \varepsilon_{v}^{p}, d \varepsilon_{s}^{p}=$ plastic, plastic volumetric, plastic shear strain increment

522 respectively;

$523 \Lambda=$ plastic multiplier;

$524 f_{I}, f_{Y}=$ Loading surface, yield surface respectively;

$G, K, h=$ elastic shear, elastic bulk, plastic modulus respectively;

$526 k_{f}, k_{g}=$ parameter controlling the shape of yield surface, plastic potential surface

527 respectively;

$528 M_{f}=$ stress ratio at the apex of yield surface;

$529 M_{g}, M_{g 0}=$ critical stress ratio at current, reference temperature respectively;

$530 \quad p^{\prime}, \bar{p}^{\prime}=$ current, mapping mean effective stress respectively; 
$531 p_{c T}^{\prime}, p_{c 0}^{\prime}=$ pre-consolidation pressure in loading surface at current, reference

532 temperature respectively;

$533 \bar{p}_{c T}^{\prime}, \bar{p}_{c 0}^{\prime}=$ pre-consolidation pressure at current, reference temperature respectively;

$534 q, \bar{q}=$ current, mapping deviator stress respectively;

$535 r, r_{0}=$ reverse of OCR at current, reference temperature respectively;

$536 s=$ parameter controlling the rate of evolution of the slope of the stress--strain

537 relation;

$538 T, T_{0}=$ current, reference temperature respectively;

$539 \mathbf{D}_{e}, \mathbf{D}_{e p}, \mathbf{D}_{e t}=$ elastic, elasto-plastic, temperature stiffness matrix respectively;

$540 \mathbf{m}=$ unit vector. 


\section{Appendix A}

557 The consistency condition of loading surface in ACC2-T model is adopted herein:

$558\left(\frac{\partial f_{I}}{\partial \boldsymbol{\sigma}^{\prime}}\right)^{t}: d \boldsymbol{\sigma}^{\prime}+\frac{\partial f_{I}}{\partial T} d T+\frac{\partial f_{I}}{\partial \bar{p}_{c 0}^{\prime}} d \bar{p}_{c 0}^{\prime}+\frac{\partial f_{I}}{\partial r_{0}} d r_{0}=0$

559 The plastic multiplier $\Lambda$ and the plastic modulus $h$ are obtained in non-isothermal

560 condition:

$561 \quad d \boldsymbol{\varepsilon}^{p}=\Lambda \frac{\partial g_{I}}{\partial \boldsymbol{\sigma}^{\prime}}$

$\Lambda=-\frac{\left(\frac{\partial f_{I}}{\partial \boldsymbol{\sigma}^{\prime}}\right)^{t}: d \boldsymbol{\sigma}^{\prime}+\frac{\partial f_{I}}{\partial T} d T}{\frac{\partial f_{I}}{\partial \bar{p}_{c 0}^{\prime}} \frac{v}{\lambda-k} \bar{p}_{c 0}^{\prime} \frac{\partial g_{I}}{\partial p^{\prime}}+\frac{\partial f_{I}}{\partial r_{0}} \frac{v}{\lambda-k} s\left(1-r_{0}\right)\left(\frac{\partial g_{I}}{\partial p^{\prime}}+A_{d} \frac{\partial g_{I}}{\partial q}\right)}$

$563 \quad h=\frac{v}{\lambda-k}\left(\frac{\partial f_{I}}{\partial \bar{p}_{c 0}^{\prime}} \bar{p}_{c 0}^{\prime} \frac{\partial g_{I}}{\partial p^{\prime}}+\frac{\partial f_{I}}{\partial r_{0}} s\left(1-r_{0}\right)\left(\frac{\partial g_{I}}{\partial p^{\prime}}+A_{d} \frac{\partial g_{I}}{\partial q}\right)\right)$

564 The total strain increment is made up of mechanical elastic strain increment, thermal

565 elastic strain increment and plastic strain increment.

$566 d \boldsymbol{\varepsilon}=d \boldsymbol{\varepsilon}_{\sigma^{\prime}}^{e}+d \boldsymbol{\varepsilon}_{T}^{e}+d \boldsymbol{\varepsilon}^{p}$

567 The thermal elastic strain increment $d \boldsymbol{\varepsilon}_{T}^{e}$ is defined as:

$568 d \boldsymbol{\varepsilon}_{T}^{e}=-\frac{1}{3} \mathbf{m} \alpha_{1} d T$

569 where $\mathbf{m}$ is the column vector with 1 at normal stress entries and 0 at shear stress entries.

570 By substituting Eq. A-6 into Eq. A-5, the general incremental stress-strain relation

571 can be expressed:

$572 d \boldsymbol{\sigma}^{\prime}=\mathbf{D}_{e} d \boldsymbol{\varepsilon}_{\sigma^{\prime}}^{e}=\mathbf{D}_{e}\left(d \boldsymbol{\varepsilon}+\frac{1}{3} \mathbf{m} \alpha_{1} d T-d \boldsymbol{\varepsilon}^{p}\right)$

573 where $\mathbf{D}_{e}$ is the mechanical elastic matrix. 
574 By substituting the plastic multiplier into Eq. A-7, the differential stress-strain

575 equations can be obtained:

$576 d \boldsymbol{\sigma}^{\prime}=\mathbf{D}_{e p} d \boldsymbol{\varepsilon}+\mathbf{D}_{e t} d T$

577 where $\mathbf{D}_{e p}, \mathbf{D}_{e t}$ are the mechanical elasto-plastic matrix and the thermal elasto-plastic

578 matrix, respectively.

$579 \quad \mathbf{D}_{e p}=\mathbf{D}_{e}-\frac{\mathbf{D}_{e} \frac{\partial g_{I}}{\partial \boldsymbol{\sigma}^{\prime}}\left(\frac{\partial f_{I}}{\partial \boldsymbol{\sigma}^{\prime}}\right)^{t} \mathbf{D}_{e}}{\left(\frac{\partial f_{I}}{\partial \boldsymbol{\sigma}^{\prime}}\right)^{t} \mathbf{D}_{e} \frac{\partial g_{I}}{\partial \boldsymbol{\sigma}^{\prime}}+h}$

580

$$
\mathbf{D}_{e t}=\frac{\mathbf{D}_{e} \frac{\partial g_{I}}{\partial \boldsymbol{\sigma}^{\prime}}\left[-\frac{1}{3}\left(\frac{\partial f_{I}}{\partial \boldsymbol{\sigma}^{\prime}}\right)^{t} \mathbf{D}_{e} \mathbf{m} \alpha_{1}-\frac{\partial f_{I}}{\partial T}\right]}{\left(\frac{\partial f_{I}}{\partial \boldsymbol{\sigma}^{\prime}}\right)^{t} \mathbf{D}_{e} \frac{\partial g_{I}}{\partial \boldsymbol{\sigma}^{\prime}}+h}+\frac{1}{3} \mathbf{D}_{e} \mathbf{m} \alpha_{1}
$$




\section{Appendix B}

Assume the soil is loaded and heated from Point A to Point B under two different 598 loading paths $\mathrm{I}(A \rightarrow C \rightarrow B)$ and $\mathrm{II}(A \rightarrow D \rightarrow B)$ in Fig.5. The soil is at the initial stress 599 state $\left(p_{0}^{\prime}, r_{0}, p_{c 0}^{\prime}, T_{1}\right)$ which automatically satisfies the yield condition:

600 $f_{I 0}=p_{0}^{\prime}-r_{0} p_{c 0}^{\prime} \exp \left[-\alpha_{0} r_{0}^{n_{c}}\left(T_{1}-T_{0}\right)\right]=0$

601 Under loading path I, the soil element is isotropically loaded to stress point $C$ $602\left(p_{0}^{\prime}+\Delta p_{1}^{\prime}, r_{1}, p_{c 1}^{\prime}, T_{1}\right)$ at constant temperature $T_{1}$.

603

$$
f_{I 1}=p_{0}^{\prime}+\Delta p_{1}^{\prime}-r_{1} p_{c 1}^{\prime} \exp \left[-\alpha_{0} r_{1}^{n_{c}}\left(T_{1}-T_{0}\right)\right]=0
$$

$604 \quad p_{c 1}^{\prime}=p_{c 0}^{\prime} \exp \left[\frac{v}{\lambda-\kappa} \Delta \varepsilon_{v 1}^{p}\right]$

$605 \quad r_{1}=1+\left(r_{0}-1\right) \exp \left[-\frac{v}{\lambda-\kappa} s \Delta \varepsilon_{v 1}^{p}\right]$

606 Then the soil element is heated up to stress point $B\left(p_{0}^{\prime}+\Delta p_{1}^{\prime}, r_{2}, p_{c 2}^{\prime}, T_{1}+\Delta T_{1}\right)$ at 607 constant mean effective stress $p_{0}^{\prime}+\Delta p_{1}^{\prime}$.

608

$$
f_{I 2}=p_{0}^{\prime}+\Delta p_{1}^{\prime}-r_{2} p_{c 2}^{\prime} \exp \left[-\alpha_{0} r_{2}^{n_{c}}\left(T_{1}+\Delta T_{1}-T_{0}\right)\right]=0
$$

$609 \quad p_{c 2}^{\prime}=p_{c 1}^{\prime} \exp \left[\frac{v}{\lambda-\kappa} \Delta \varepsilon_{v 2}^{p}\right]=p_{c 0}^{\prime} \exp \left[\frac{v}{\lambda-\kappa}\left(\Delta \varepsilon_{v 1}^{p}+\Delta \varepsilon_{v 2}^{p}\right)\right]$

$r_{2}=1+\left(r_{1}-1\right) \exp \left[-\frac{v}{\lambda-\kappa} s \Delta \varepsilon_{v 2}^{p}\right]=1+\left(r_{0}-1\right) \exp \left[-\frac{v}{\lambda-\kappa} s\left(\Delta \varepsilon_{v 1}^{p}+\Delta \varepsilon_{v 2}^{p}\right)\right]$

611 Under loading path II, the soil element is firstly heated up to stress point $D$ $612\left(p_{0}^{\prime}, r_{3}, p_{c 3}^{\prime}, T_{1}+\Delta T_{1}\right)$ at constant mean effective stress $p_{0}^{\prime}$

$613 f_{I 3}=p_{0}^{\prime}-r_{3} p_{c 3}^{\prime} \exp \left[-\alpha_{0} r_{3}^{n_{c}}\left(T_{1}+\Delta T_{1}-T_{0}\right)\right]=0$

$614 \quad p_{c 3}^{\prime}=p_{c 0}^{\prime} \exp \left[\frac{v}{\lambda-\kappa} \Delta \varepsilon_{v 3}^{p}\right]$

$615 \quad r_{3}=1+\left(r_{0}-1\right) \exp \left[-\frac{v}{\lambda-\kappa} s \Delta \varepsilon_{v 3}^{p}\right]$

616 Then, the soil element is isotropically loaded to stress point $B\left(p_{0}^{\prime}+\Delta p_{1}^{\prime}, r_{4}, p_{c 4}^{\prime}, T_{1}+\Delta T_{1}\right)$ 
617 at constant temperature $T_{1}+\Delta T_{1}$.

$618 f_{I 4}=p_{0}^{\prime}+\Delta p_{1}^{\prime}-r_{4} p_{c 4}^{\prime} \exp \left[-\alpha_{0} r_{4}^{n_{c}}\left(T_{1}+\Delta T_{1}-T_{0}\right)\right]=0$

$619 \quad p_{c 4}^{\prime}=p_{c 3}^{\prime} \exp \left[\frac{v}{\lambda-\kappa} \Delta \varepsilon_{v 4}^{p}\right]=p_{c 0}^{\prime} \exp \left[\frac{v}{\lambda-\kappa}\left(\Delta \varepsilon_{v 3}^{p}+\Delta \varepsilon_{v 4}^{p}\right)\right]$

620 $r_{4}=1+\left(r_{3}-1\right) \exp \left[-\frac{v}{\lambda-\kappa} s \Delta \varepsilon_{v 4}^{p}\right]=1+\left(r_{0}-1\right) \exp \left[-\frac{v}{\lambda-\kappa} s\left(\Delta \varepsilon_{v 3}^{p}+\Delta \varepsilon_{v 4}^{p}\right)\right]$

621 Compare Eqs.B-5, B-6, B-7 and Eqs.B-11, B-12, B-13, it appears clearly that the two 622 different loading paths would reach the same final stress state, namely:

$623 \quad p_{c 2}^{\prime}=p_{c 4}^{\prime}$

$624 r_{2}=r_{4}$

$625 \Delta \varepsilon_{v 1}^{p}+\Delta \varepsilon_{v 2}^{p}=\Delta \varepsilon_{v 3}^{p}+\Delta \varepsilon_{v 4}^{p}$

626 No matter Path I or Path II is followed, the plastic volumetric strain will be equal, which 627 means that plastic volumetric strain in ACC2-T model is also loading path independent. 628 629 630 631 632 633 634 635 636 637 638 639 640 641 642 


\section{References}

644 [1] Bourne-Webb PJ, Amatya B, Soga K, Amis T, Davidson C, Payne P. Energy pile test at Lambeth College, London: geotechnical and thermodynamic aspects of pile response to heat cycles. Géotechnique 2009;59:237-48.

[2] Amatya BL, Soga K, Bourne-Webb PJ, Amis T, Laloui L. Thermo-mechanical behaviour of energy piles. Geotechnique 2012;62:503-19.

[3] Mimouni T, Laloui L. Behaviour of a group of energy piles. Canadian Geotechnical Journal 2015;52:1913-29.

[4] Gens A, Sanchez M, Guimaraes LD, Alonso EE, Lloret A, Olivella S, et al. A fullscale in situ heating test for high-level nuclear waste disposal: observations, analysis and interpretation. Geotechnique 2009;59:377-99.

654 [5] Liu XC, Xiao YM, Inthavong K, Tu JY. A fast and simple numerical model for a 655 deeply buried underground tunnel in heating and cooling applications. Applied Thermal Engineering 2014;62:545-52.

[6] Campanella R G, Mitchell J K. Influence of temperature variations on soil behavior. Journal of Soil Mechanics \& Foundations Div, 1968.

[7] Eriksson L G. Temperature effects on consolidation properties of sulphide clays. International Conference on Soil Mechanics and Foundation Engineering: 13/08/198918/08/1989. Balkema Publishers, AA/Taylor \& Francis The Netherlands, 1989: 20872090 .

[8] Baldi G, Hueckel T, Peano A, Pellegrini R. Developments in modelling of thermohydro-geomechanical behaviour of Boom clay and clay-based buffer materials (volume 2). Commission of the European Communities, 1991.

[9] Delage P, Sultan N, Cui Y J. On the thermal consolidation of Boom clay. Canadian Geotechnical Journal, 2000, 37(2): 343-354.

668 [10] Yavari N, Tang AM, Pereira JM, Hassen G. Mechanical behaviour of a small-scale 669 energy pile in saturated clay. Géotechnique 2016;66:878-87.

670 [11] Ng CWW, Shi C, Gunawan A, Laloui L. Centrifuge modelling of energy piles 
671 subjected to heating and cooling cycles in clay. Géotechnique Letters 2014;4:310-6.

672 [12] Hueckel T, Pellegrini R. Thermoplastic modeling of undrained failure of saturated 673 clay due to heating. Soils and Foundations, 1991, 31(3): 1-16.

674 [13] Hueckel T, Baldi G. Thermoplasticity Of Saturated Clays - Experimental 675 Constitutive Study. J Geotech Eng-Asce 1990;116:1778-96.

676 [14] Hueckel T, Borsetto M. Thermoplasticity Of Saturated Soils And Shales: 677 Constitutive equations. J Geotech Eng-Asce 1990;116:1765-77.

678 [15] Robinet JC, Rahbaoui A, Plas F, Lebon P. A constitutive thermomechanical model 679 for saturated clays. Engineering Geology 1996;41:145-69.

680 [16] Cui Y J, Sultan N, Delage P. A thermomechanical model for saturated clays. 681 Canadian Geotechnical Journal, 2000, 37(3): 607-620.

682 [17] Graham J, Tanaka N, Crilly T, Alfaro M. Modified Cam-Clay modelling of 683 temperature effects in clays. Canadian Geotechnical Journal 2001;38:608-21.

684 [18] Abuel-Naga HM, Bergado DT, Bouazza A, Ramana GV. Volume change behaviour 685 of saturated clays under drained heating conditions: experimental results and 686 constitutive modeling. Canadian Geotechnical Journal 2007;44:942-56.

687 [19] Yao YP, Zhou AN. Non-isothermal unified hardening model: a thermo-elasto688 plastic model for clays. Géotechnique 2013;63:1328-45.

689 [20] Laloui L, François B. ACMEG-T: soil thermoplasticity model. Journal of 690 engineering mechanics, 2009, 135(9): 932-944.

691 [21] Hong PY, Pereira JM, Cui YJ, Tang AM. A two-surface thermomechanical model 692 for saturated clays. International Journal for Numerical and Analytical Methods in 693 Geomechanics 2016;40:1059-80.

694 [22] Hong PY, Pereira JM, Tang AM, Cui YJ. On some advanced thermo-mechanical 695 models for saturated clays. International Journal for Numerical and Analytical Methods 696 in Geomechanics 2013;37:2952-71.

697 [23] Demars K R, Charles R D . Soil volume changes induced by temperature cycling. 698 Canadian Geotechnical Journal, 2011, 19(2):188-194. 
699 [24] Plum R L, Esrig M I. Some temperature effects on soil compressibility and pore 700 water pressure. Special Report-Highway Research Board, 1969 (103): 231.

701 [25] Di Donna A, Laloui L. Response of soil subjected to thermal cyclic loading: 702 Experimental and constitutive study. Engineering Geology 2015;190:65-76.

703 [26] Ng CWW, Shi C, Gunawan A, Laloui L, Liu HL. Centrifuge modelling of heating 704 effects on energy pile performance in saturated sand. Canadian Geotechnical Journal $705 \quad 2015 ; 52: 1045-57$.

706 [27] Vega A, McCartney JS. Cyclic heating effects on thermal volume change of silt. 707 Environmental Geotechnics 2015, 2: 257-68.

708 [28] Zhou C, Fong KY, Ng CWW. A new bounding surface model for thermal cyclic 709 behaviour. International Journal for Numerical and Analytical Methods in 710 Geomechanics 2017;41:1656-66.

711 [29] Ma QJ, Ng CWW, Masin D, Zhou C. An approach for modelling volume change 712 of fine-grained soil subjected to thermal cycles. Canadian Geotechnical Journal $713 \quad 2017 ; 54: 896-901$.

714 [30] Coussy, O. (2004). Poromechanics, John Wiley and Sons, Ltd.

715 [31] McDowell GR, Hau KW. A generalised Modified Cam clay model for clay and 716 sand incorporating kinematic hardening and bounding surface plasticity. Granular 717 Matter 2004;6:11-6.

718 [32] Zhang S, Leng W, Zhang F, et al. A simple thermo-elastoplastic model for 719 geomaterials. International Journal of Plasticity, 2012, 34: 93-113.

720 [33] Collins I F , Houlsby G T . Application of thermomechanical principles to the 721 modelling of geotechnical materials. Proceedings of the Royal Society A: Mathematical, 722 Physical and Engineering Sciences, 1997, 453(1964):1975-2001.

723 [34] Lebon, Georgy, Jou, et al. Understanding non-equilibrium thermodynamics. 2008.

724 [35] B. Spang, Excel add-in for properties of water and steam in si-units, available from 725 http://www.cheresources.com/ iapwsif97.shtml, 2002 (2002).

726 [36] Yao Y P, Sun D A, Matsuoka H . A unified constitutive model for both clay and 
727 sand with hardening parameter independent on stress path $[\mathrm{J}]$. Computers \& 728 Geotechnics, 2008, 35(2):210-222.

729 [37] Yao Y P, Sun D A, Luo T . A critical state model for sands dependent on stress 730 and density[J]. International Journal for Numerical and Analytical Methods in 731 Geomechanics, 2004, 28(4): 323-337.

732 [38] Lê T. Comportement thermo-hydro-mécanique de l'argile de boom. PhD Thesis, 733 École Nationale des Ponts et Chaussées, France 2008.

734 [39] Borja R I, Tamagnini C, Amorosi A. Coupling plasticity and energy-conserving 735 elasticity models for clays. Journal of Geotechnical and Geoenvironmentol Engineering, 736 1997, 123(10): 948-957.

737 [40] Pastén C, Castillo E, Chong S H. Thermo-mechanical ratcheting in soil-structure 738 interfaces. Acta Geotechnica, 2019, 14: 1561-1569.

739 [41] Zymnis, D M, Whittle A J, Cheng X. Simulation of long-term thermo-mechanical 740 response of clay using an advanced constitutive model. Acta Geotechnica. 2019, 14: $741 \quad 295-31$. 


\section{LIST OF TABLES}

756 Table.1 Model parameters of different fine-grained soils 
Table.1 Model parameters of different fine-grained soils

\begin{tabular}{|c|c|c|c|c|c|c|c|c|c|c|c|c|c|c|c|}
\hline Parameters & $\kappa$ & $\lambda$ & $\bar{p}_{c 0,0}^{\prime}(\mathrm{kPa})$ & $r_{0,0}$ & $v$ & $\alpha_{0}\left({ }^{\circ} C^{-1}\right)$ & $\alpha_{1}\left({ }^{\circ} C^{-1}\right)$ & $S$ & $T_{0}\left({ }^{\circ} C\right)$ & $n_{c}$ & $M_{g 0}$ & $M_{f}$ & $A_{d}$ & $k_{f}$ & $k_{g}$ \\
\hline Boom clay $[8]$ & 0.02 & 0.18 & 6000 & 0.33 & - & $5 \times 10^{-3}$ & $5 \times 10^{-5}$ & 8 & 21.5 & -1 & 0.67 & 0.67 & 0.1 & 0.7 & 0.9 \\
\hline Geneva clay [25] & 0.017 & 0.062 & 125 & 1 & 0.3 & $5.2 \times 10^{-3}$ & $1.5 \times 10^{-5}$ & 12 & 20 & 3.5 & 0.94 & 0.94 & 0.1 & 1.1 & 1.1 \\
\hline Bonny silt[27] & 0.011 & 0.075 & 1200 & $*$ & 0.3 & $1.6 \times 10^{-3}$ & $3.5 \times 10^{-5}$ & 10 & 18 & 4 & 1.3 & 1.3 & 0.2 & 1.1 & 1.1 \\
\hline
\end{tabular}

'-' means the parameters are irrelevant to the simulations in this study.

‘*' means different data are mentioned in this study. 


\section{List of Figure Captions}

Fig.1 Permanent reduction in void ratio due to temperature cycles versus overconsolidation ratio (replotted from Demars and Charles[23])

Fig. 2 Yield locus in (a): (p, q) plane at two different temperatures (with $\left.\mathrm{T}_{1}>\mathrm{T}_{0}\right)$ and (b): two loading yield limits $I L Y$ and $L Y$ in (p'-T) plane.

Fig.3 Yield limits in (p', T) plane: (a) TEAM Model (b) ACC2-T Model

Fig.4 Evolution of yield limits in (p', T) plane during one heating and cooling cycle

Fig.5 Predicted response of two loading paths in mean effective stress and temperature Plane

Fig.6 Calibration process of ACC2-T model on set of material parameters for Boom clay: (a) isotropic compression test; (b) one heating-cooling cycle at normal consolidated state; (c) multiple thermal cycles; (d) triaxial compression test at over-consolidated state

Fig.7 Isotropic/one-dimensional compression tests of Boom clay, Geneva clay and Bonny silt

Fig. 8 Volumetric strain change of Boom clay due to one heating and cooling cycle with different mean effective stresses under drained condition: (a) TEAM model (b) ACC2-T model

Fig. 9 Triaxial drained behavior of Boom clay at reference temperature $25^{\circ} \mathrm{C}$ and high temperature $76^{\circ} \mathrm{C}$ : (a) deviatoric stress vs axial strain; (b) volumetric strain vs axial strain;

Fig.10 Thermal cyclic behaviors of normal consolidated Geneva clay under drained 
condition: (a) comparison between ACC2-T model with $n_{c}=3.5$ (best fit) and TEAM model; (b) ACC2-T model with $n_{c}=0$ and $n_{c}=10$; (c) volumetric strain increment due to each thermal cycle by ACC2-T model

Fig.11 Thermal cyclic behaviors of Bonny silt with different OCRs under drained condition

Fig.12 Excess pore water pressure accumulation of Pontida clay due to thermal cycles under undrained condition: (a) ACC2-T model; (b) TEAM model

Fig. 13 Correlation between thermal accumulation parameter $n_{c}$ and plasticity index $I_{p}$ 


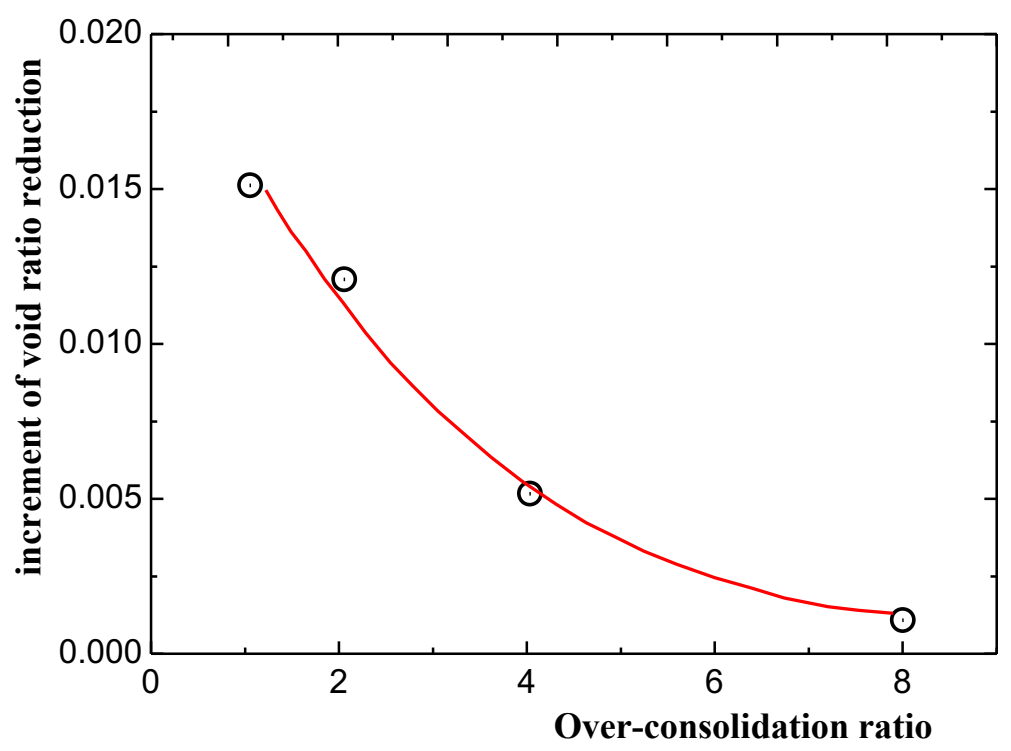

Fig.1 Permanent reduction in void ratio due to temperature cycles versus overconsolidation ratio (replotted from Demars and Charles [23]) 


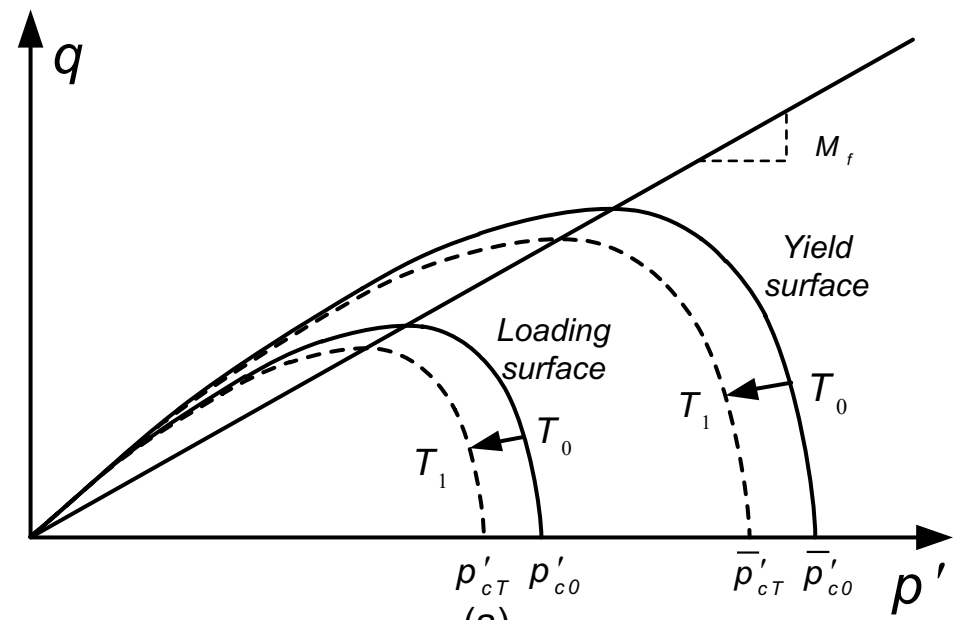

(a)

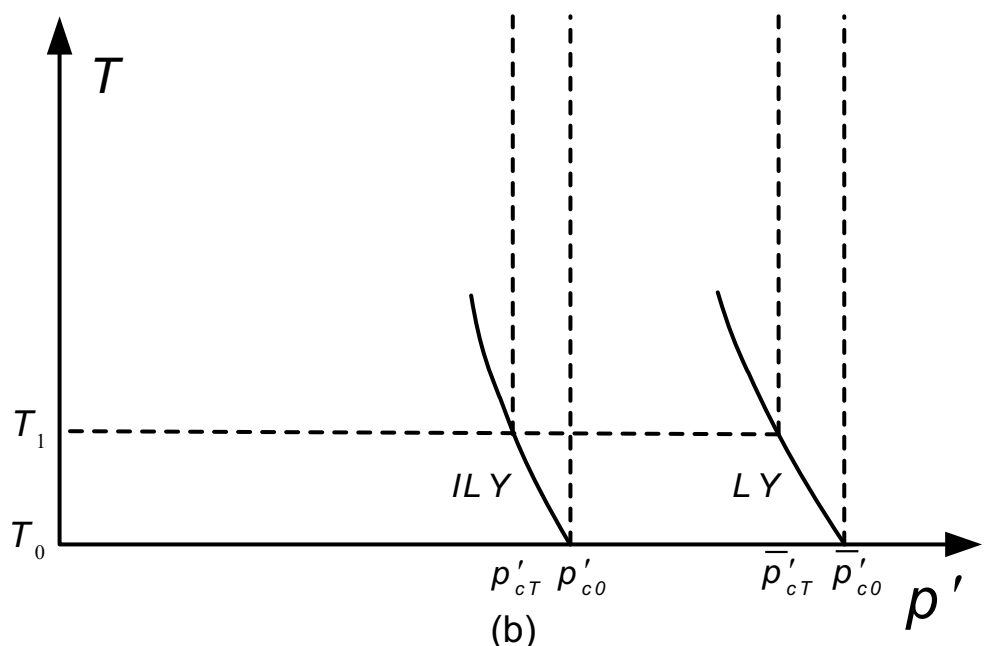

Fig.2 Yield locus in (a): (p', q) plane at two different temperatures (with $\mathrm{T}_{1}>\mathrm{T}_{0}$ ) and (b): two loading yield limits $I L Y$ and $L Y$ in $\left(\mathrm{p}^{\prime}-\mathrm{T}\right)$ plane. 


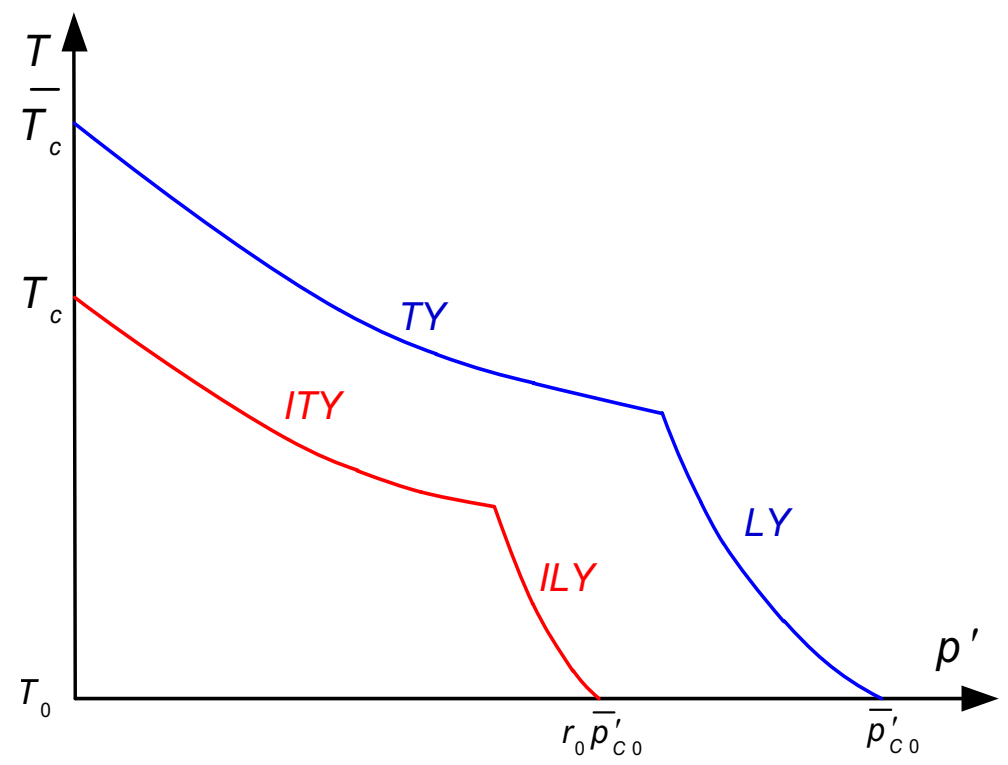

(a)

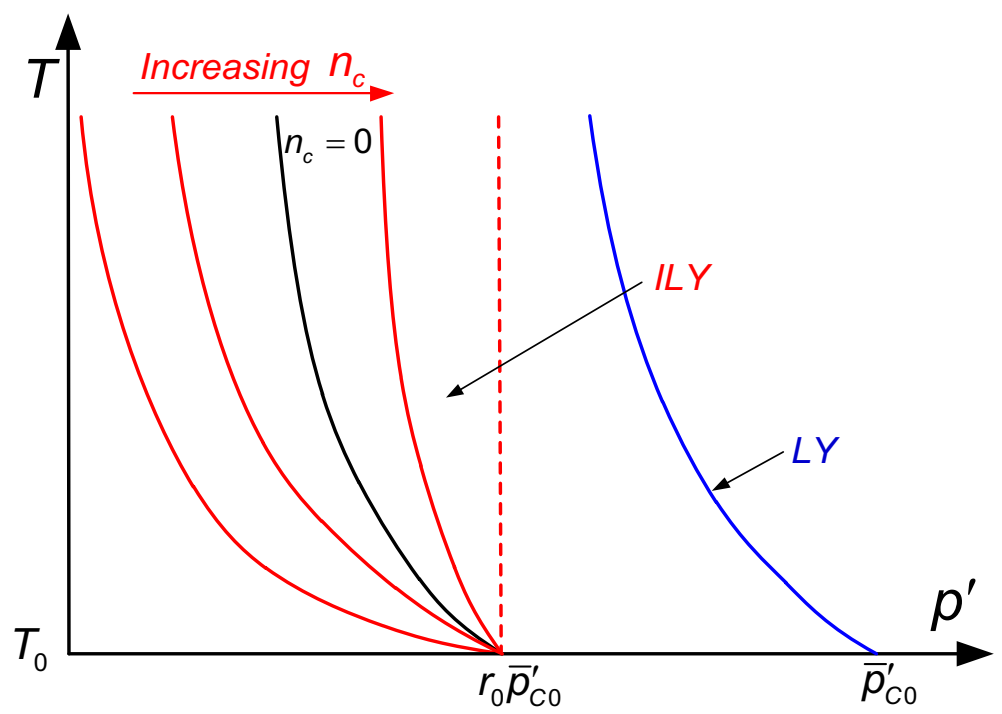

(b)

Fig.3 Yield limits in (p', T) plane: (a) TEAM Model (b) ACC2-T Model 


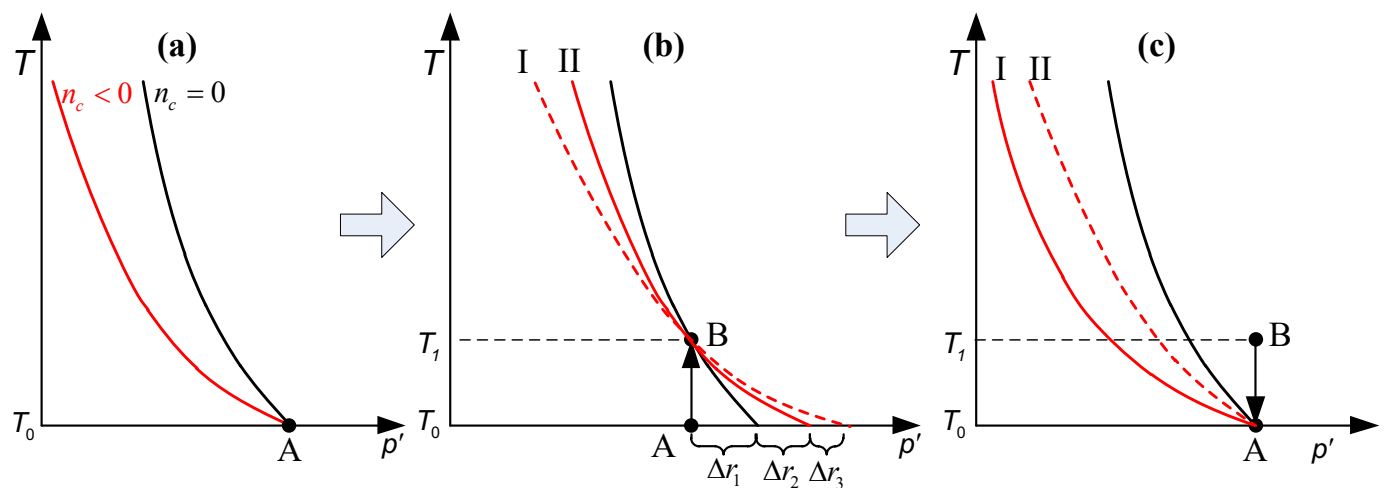

Fig.4 Evolution of yield limits in ( $\left.\mathrm{p}^{\prime}, \mathrm{T}\right)$ plane during one heating and cooling cycle 


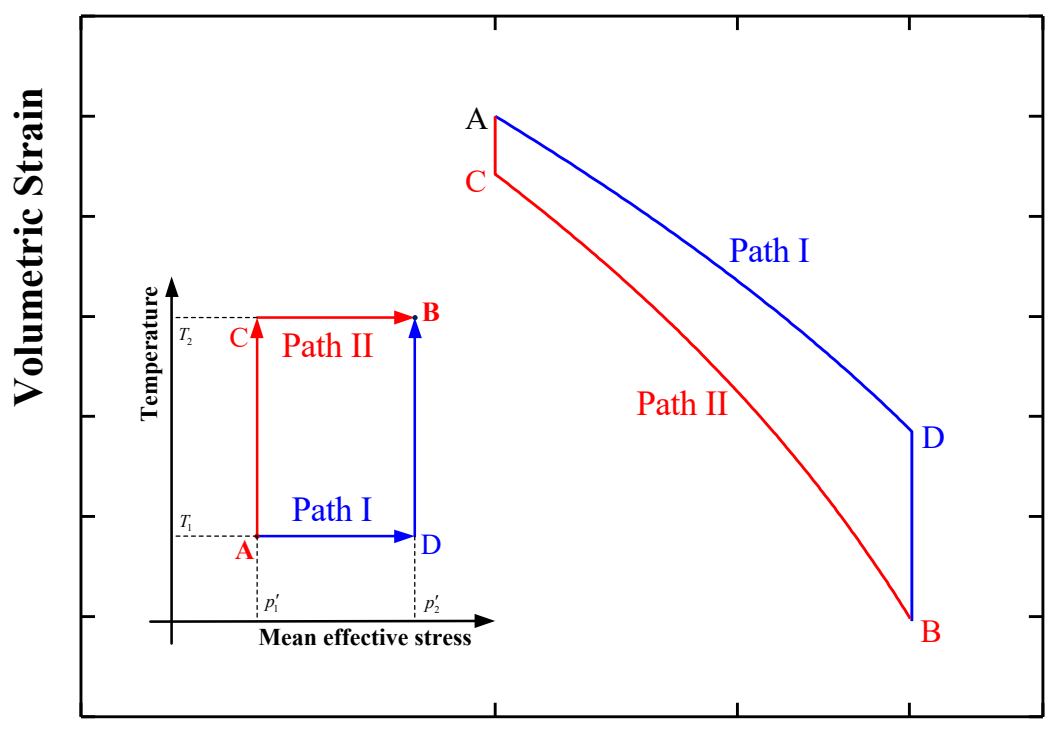

Mean effective stress

Fig.5 Predicted response of two loading paths in mean effective stress and temperature plane 


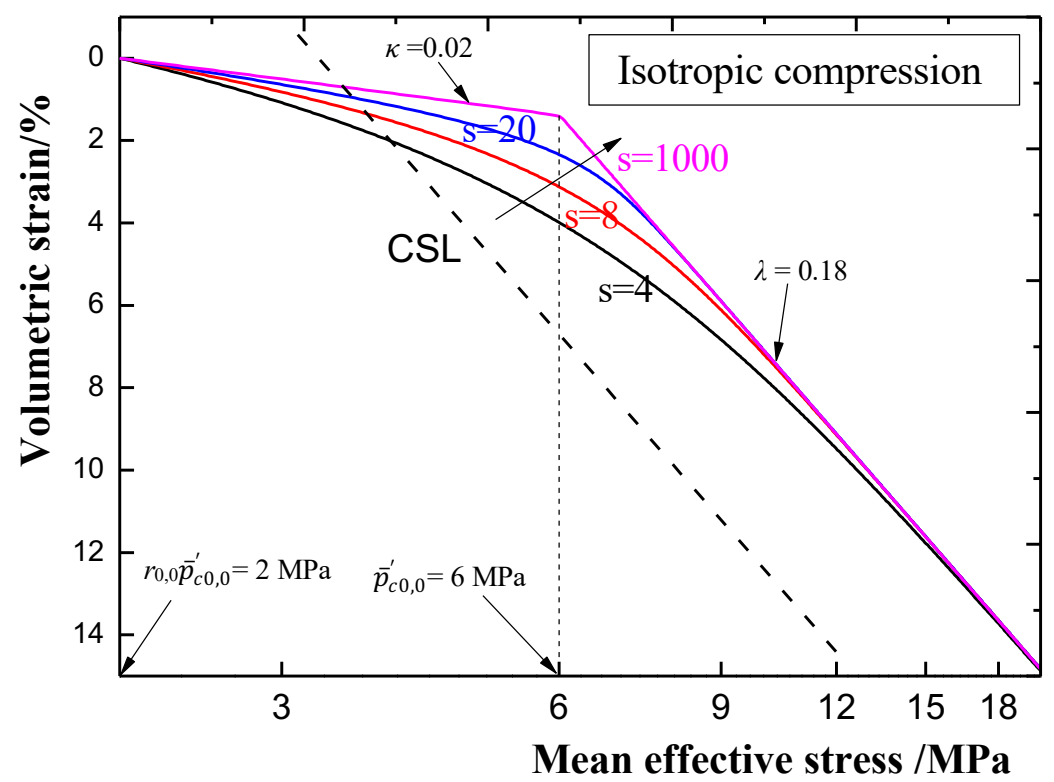

(a)

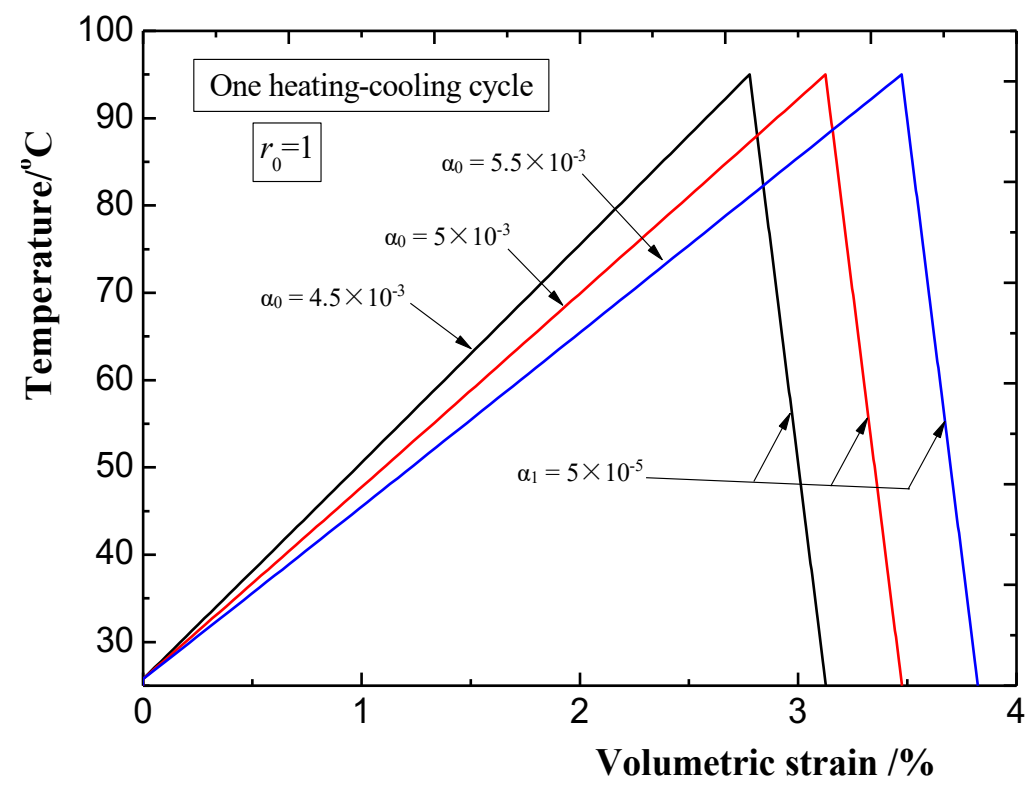

(b) 


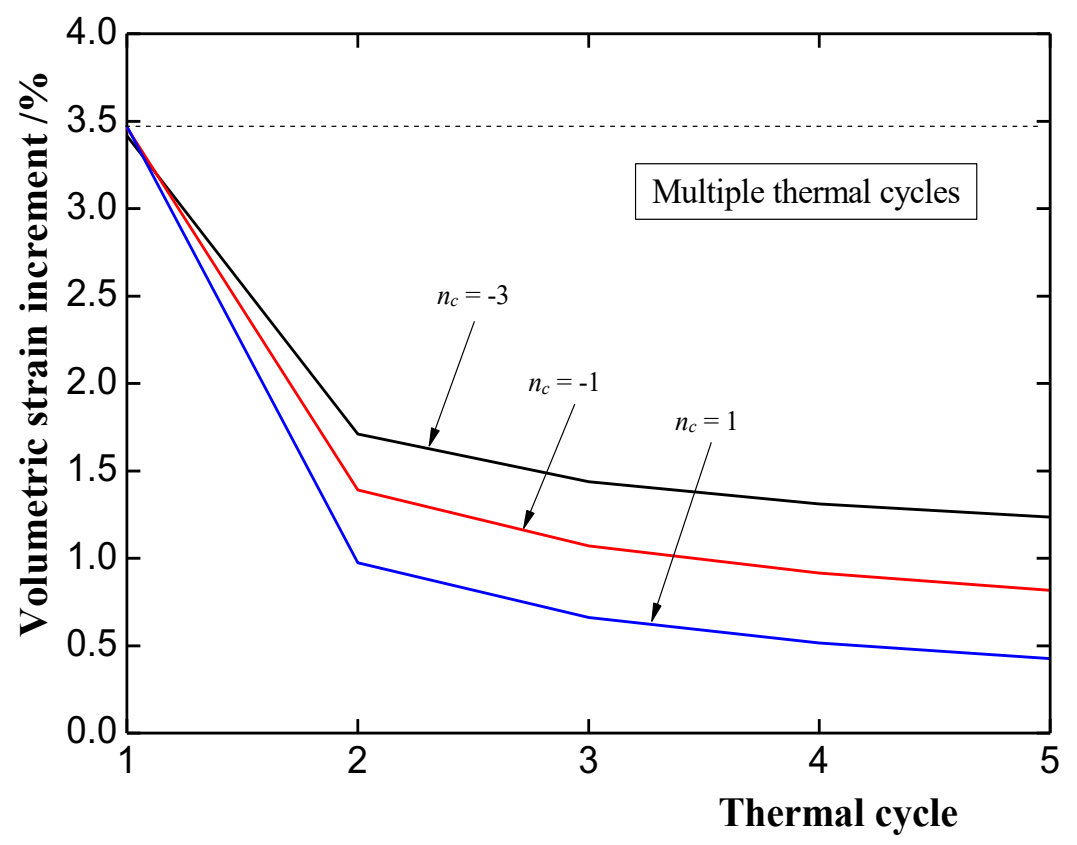

(c)

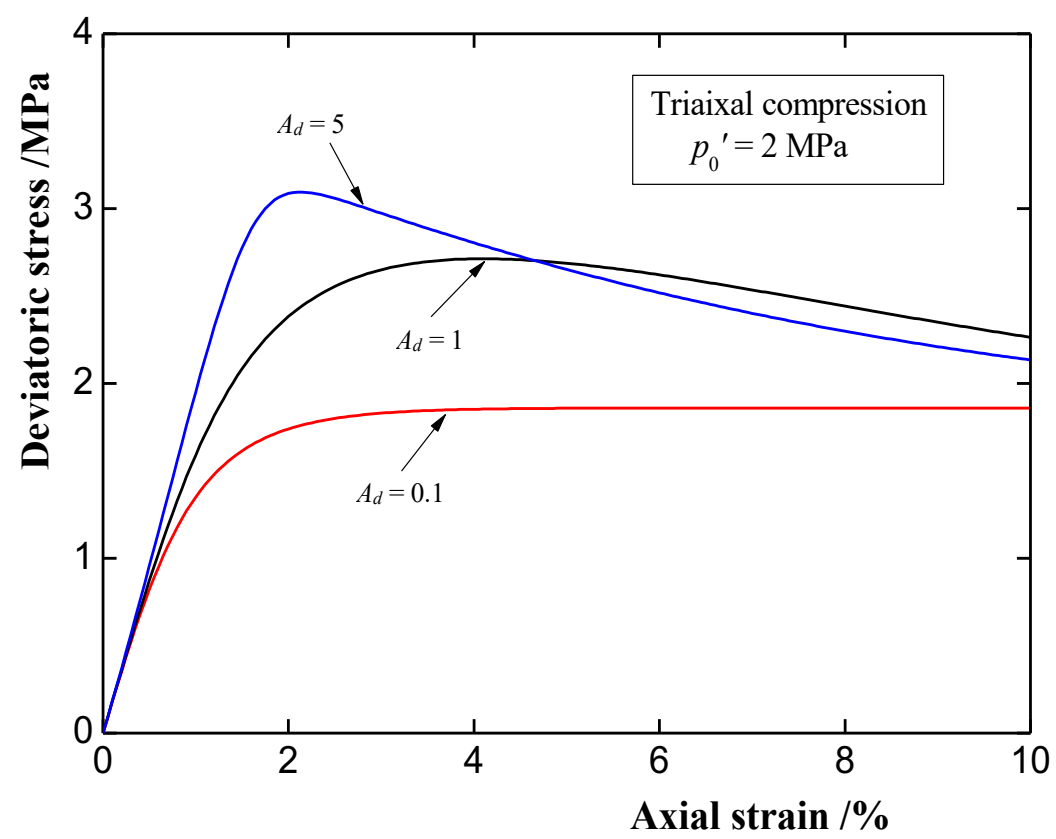

(d)

Fig.6 Calibration process of ACC2-T model on set of material parameters for Boom clay: (a) isotropic compression test; (b) one heating-cooling cycle at normal consolidated state; (c) multiple thermal cycles; (d) triaxial compression test at over-consolidated state 


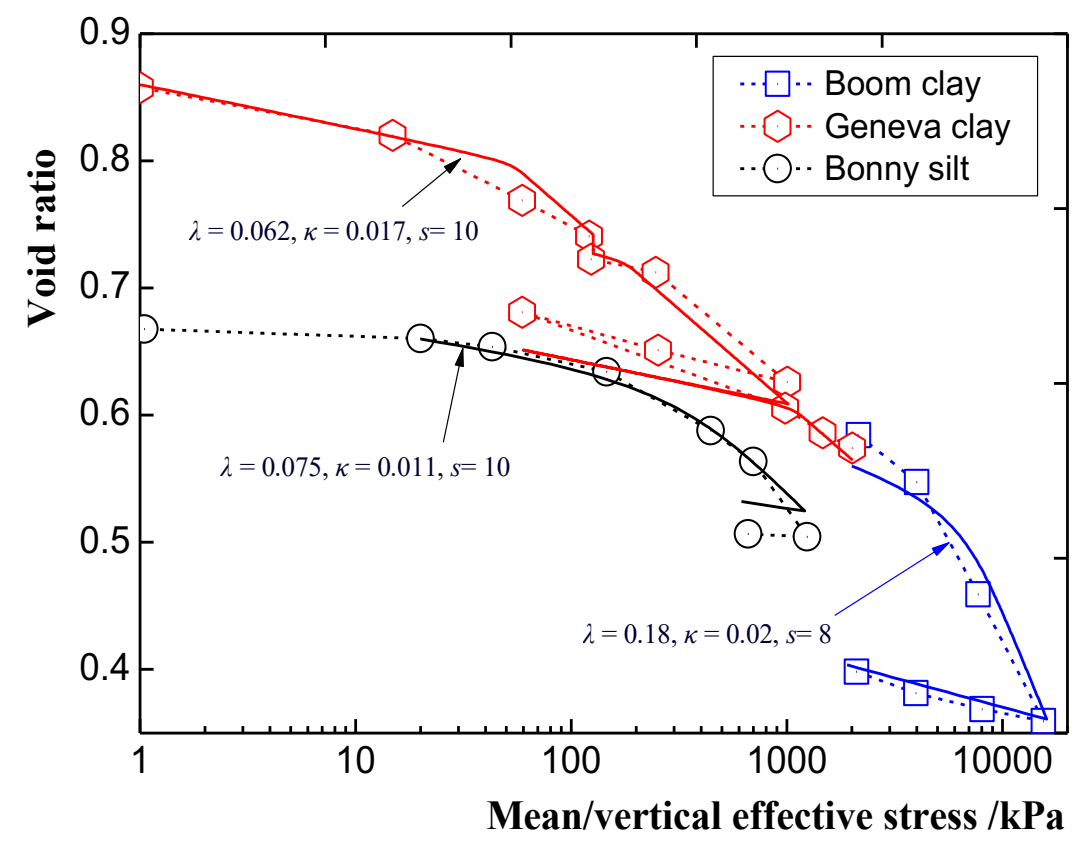

Fig.7 Isotropic/one-dimensional compression tests of Boom clay, Geneva clay and Bonny silt

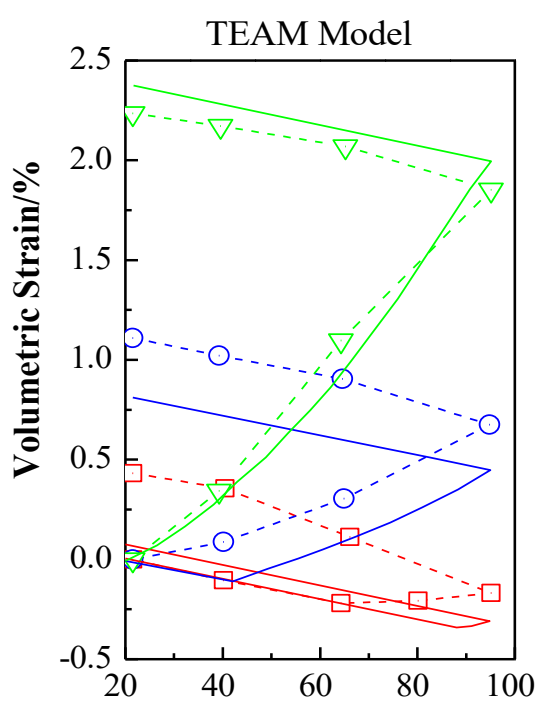

(a)

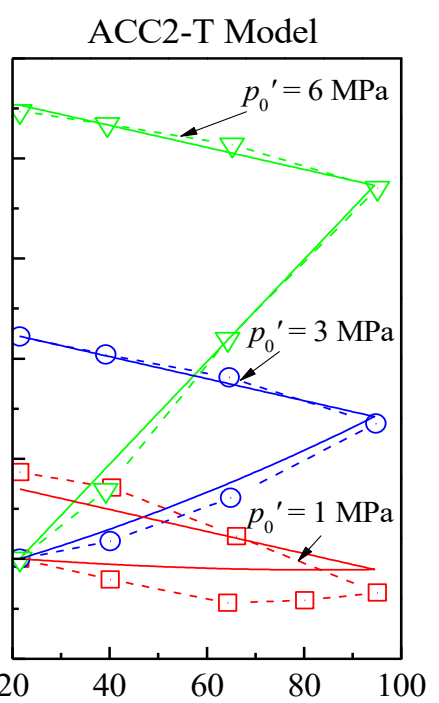

(b)

Fig. 8 Volumetric strain change of Boom clay due to one heating and cooling cycle with different mean effective stresses: (a) TEAM model (b) ACC2-T model 


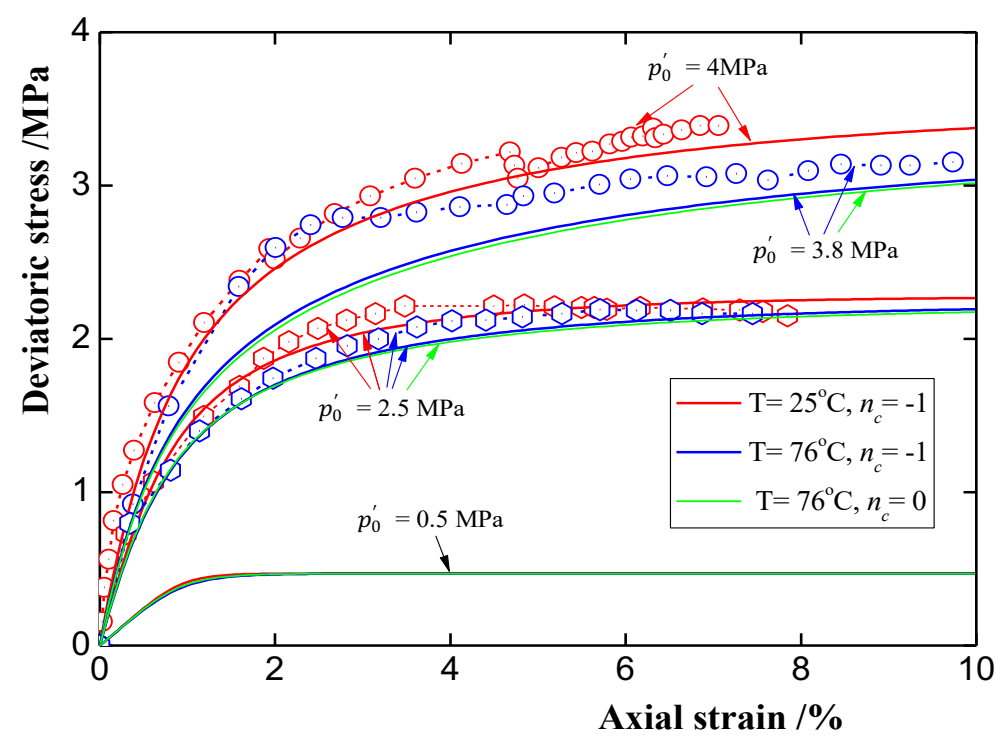

(a)

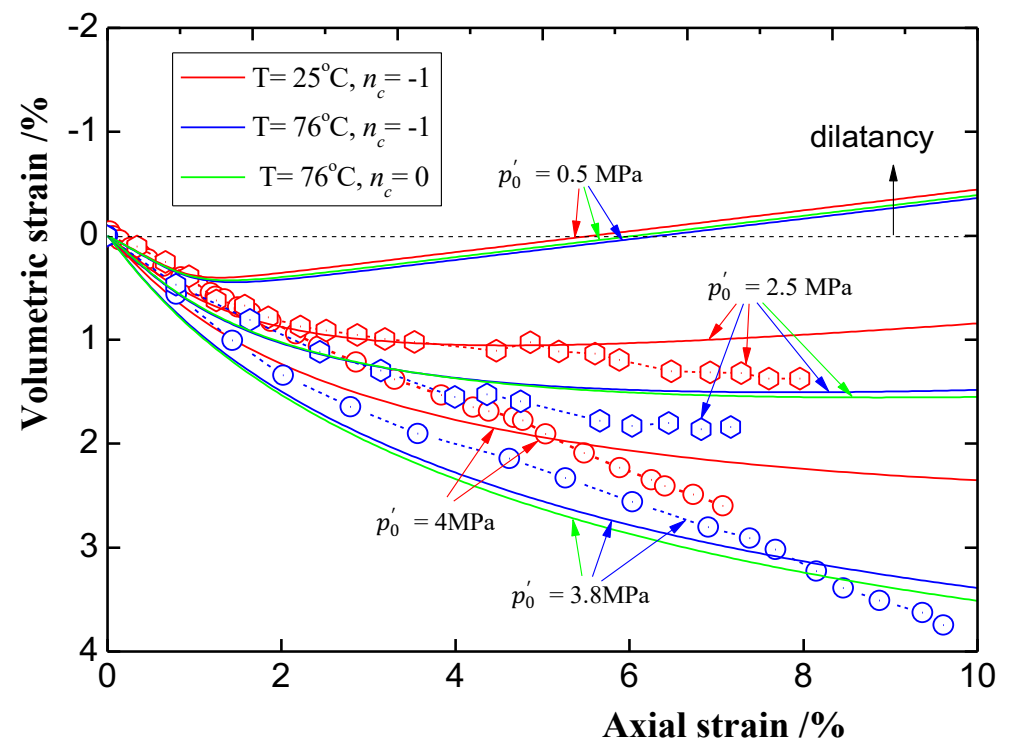

(b)

Fig. 9 Triaxial drained behaviors of Boom clay at room temperature $25{ }^{\circ} \mathrm{C}$ and high temperature $76{ }^{\circ} \mathrm{C}$ : (a) deviatoric stress vs axial strain; (b) volumetric strain vs axial strain; 


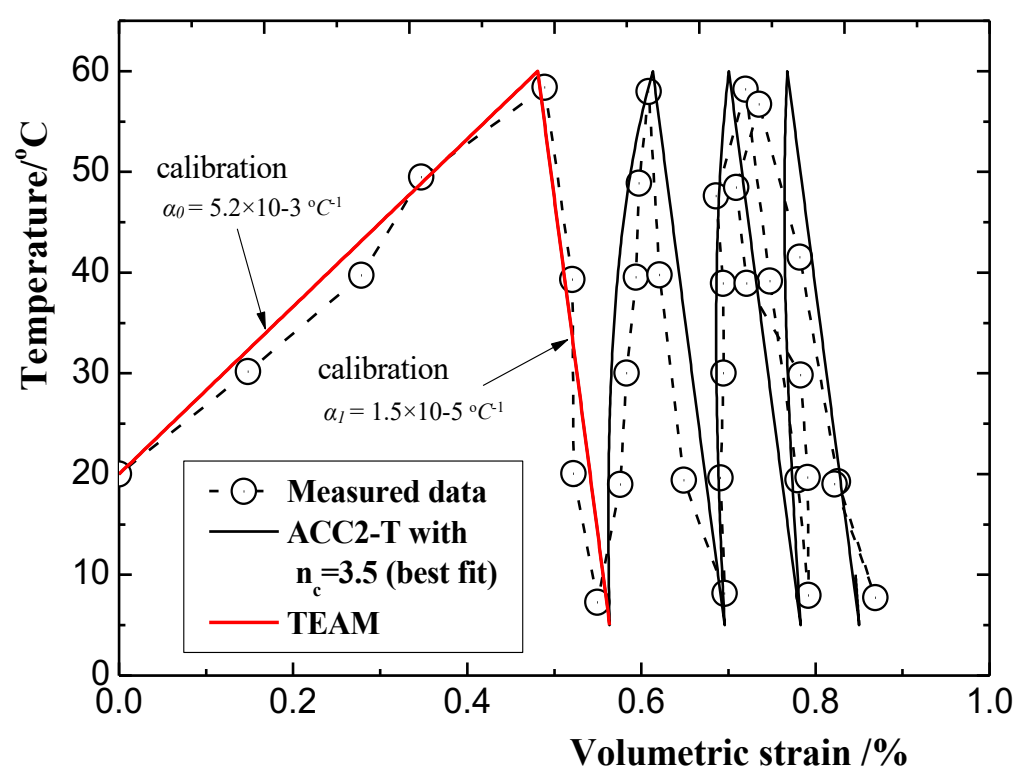

(a)

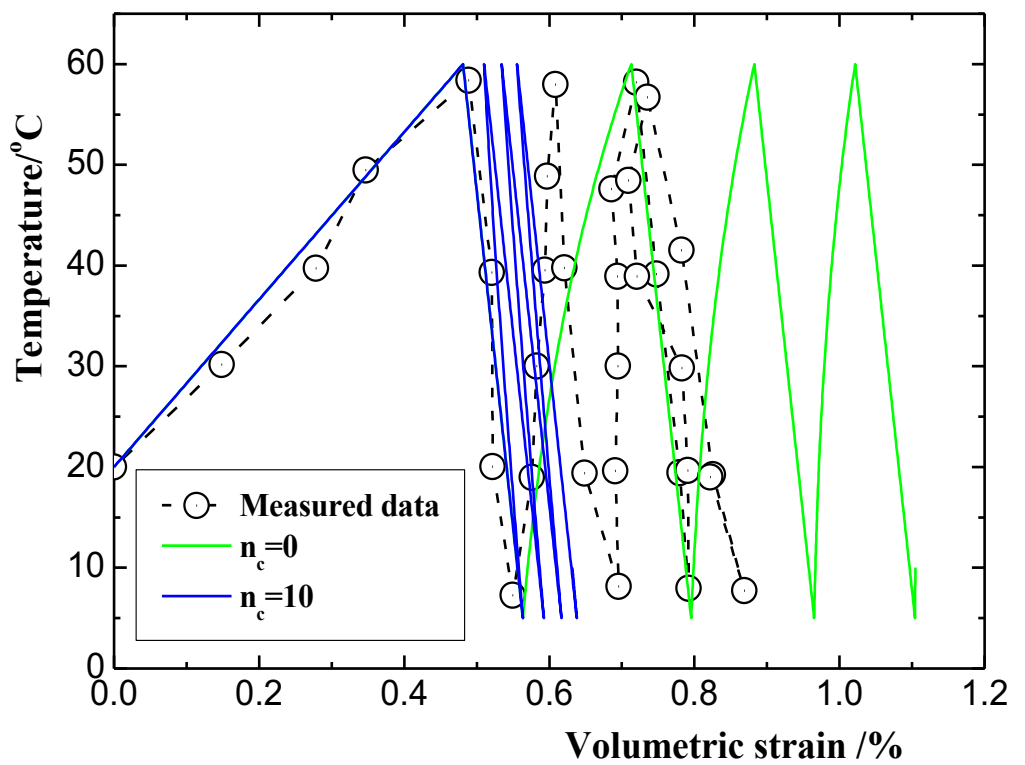

(b) 


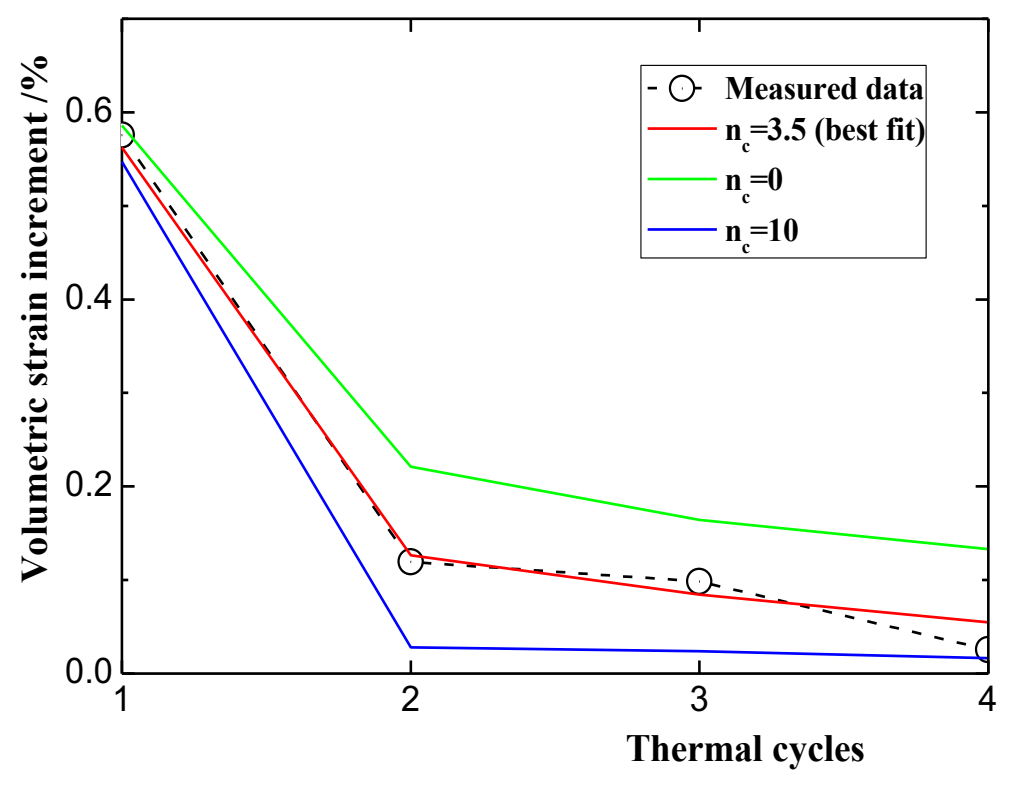

(c)

Fig.10 Thermal cyclic behaviors of normal consolidated Geneva clay under drained condition: (a) comparison between ACC2-T model with $n_{c}=3.5$ (best fit) and TEAM model; (b) ACC2-T model with $\mathrm{n}_{\mathrm{c}}=0$ and $\mathrm{n}_{\mathrm{c}}=10$; (c) volumetric strain increment due to each thermal cycle by ACC2-T model

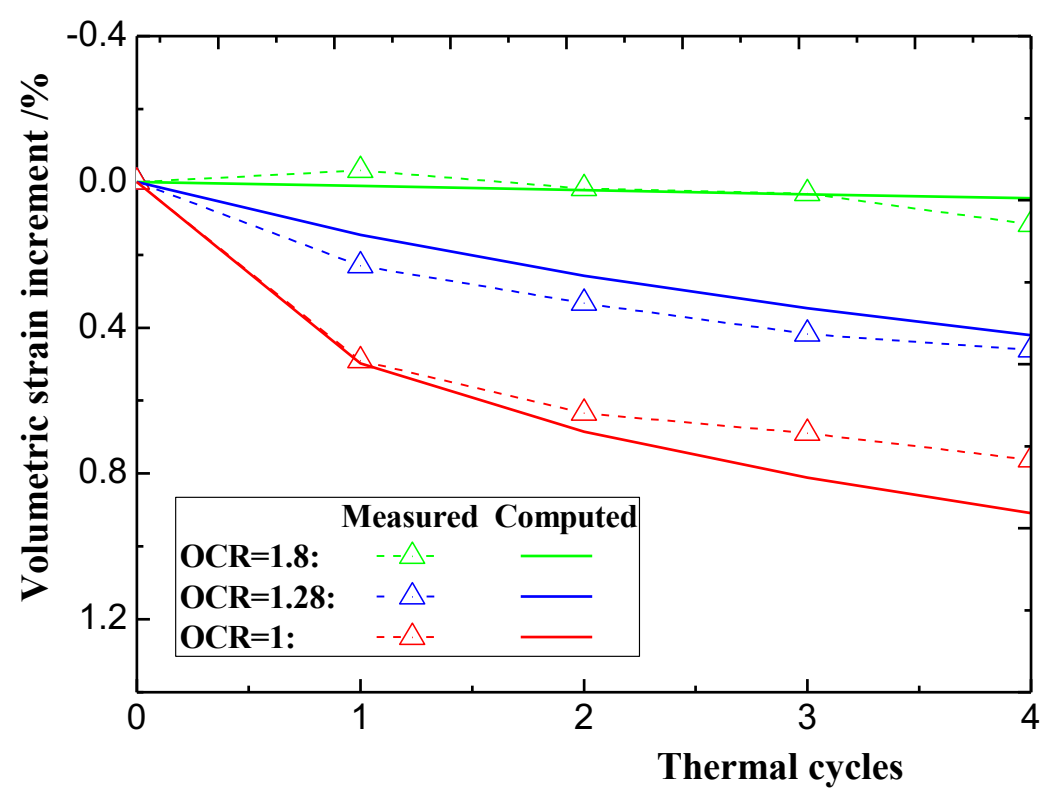

Fig.11 Accumulated strain behavior of Bonny Silt with different OCRs under drained condition 


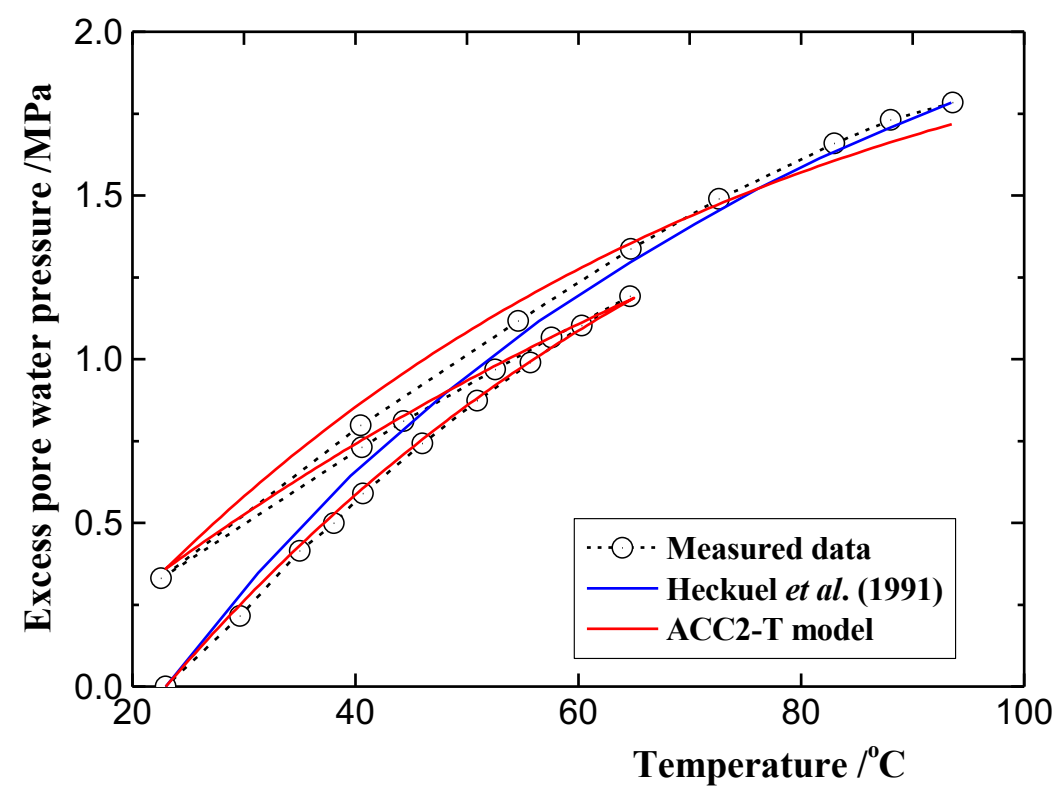

(a)

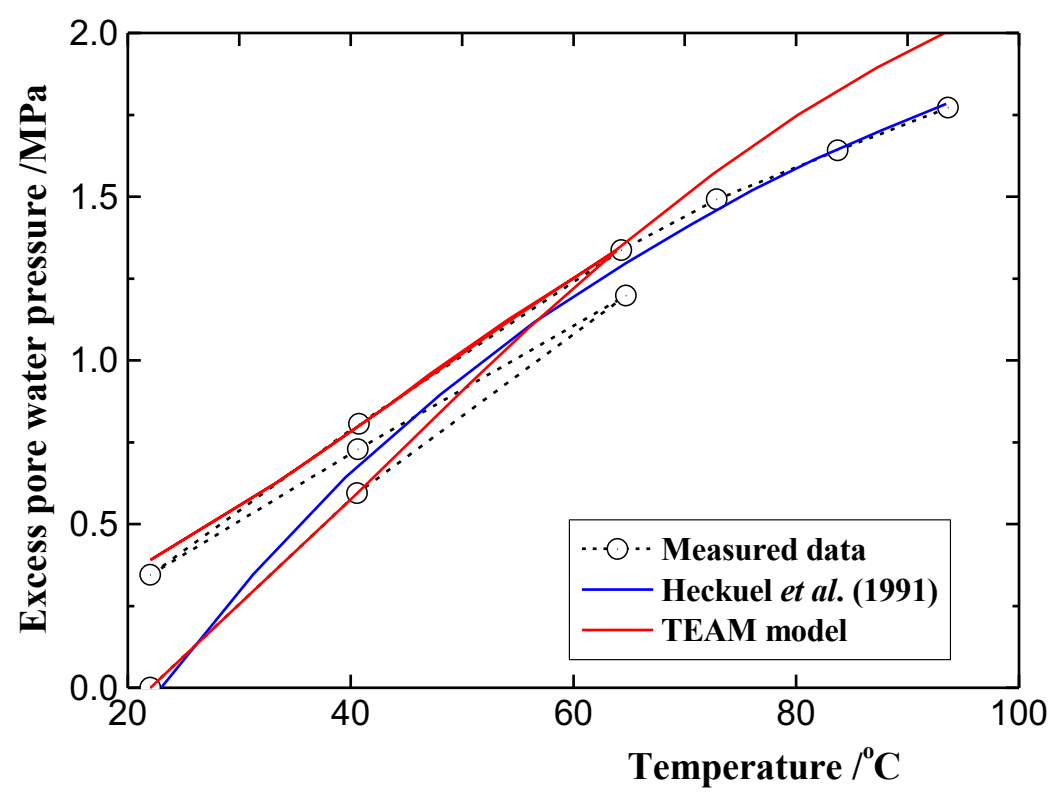

(b)

Fig.12 Excess pore water pressure accumulation of Pontida clay due to thermal cycles under undrained condition: (a) ACC2-T model; (b) TEAM model 


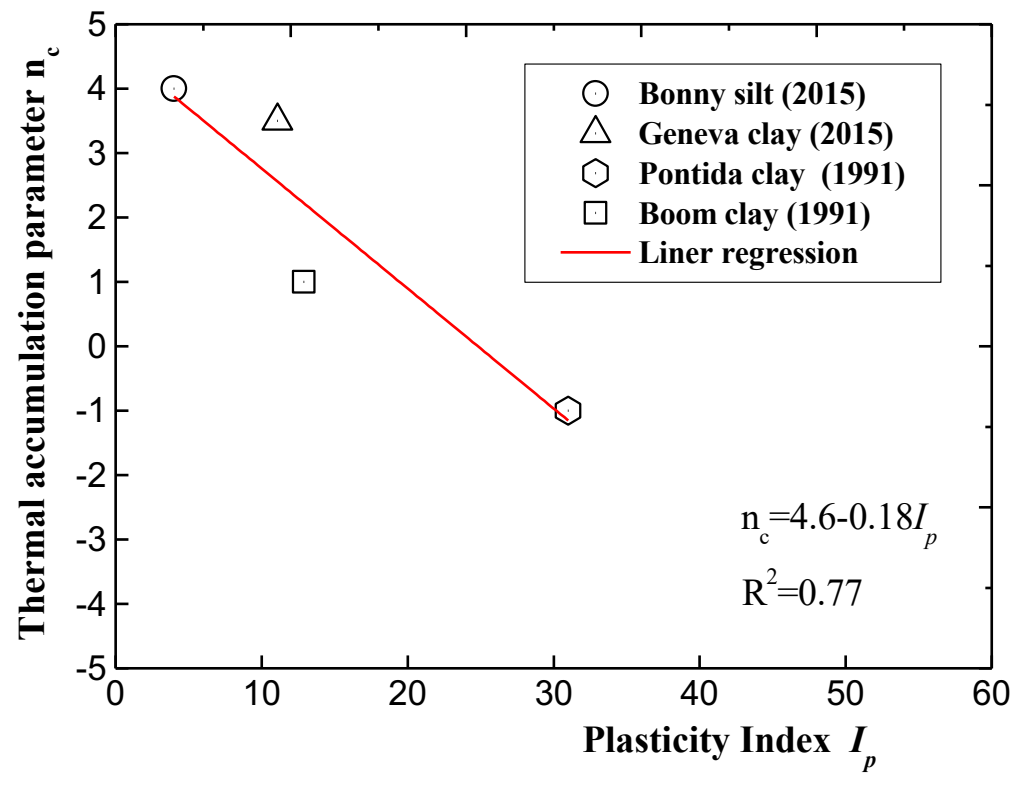

Fig. 13 Correlation between thermal accumulation parameter $n_{c}$ and plasticity index $I_{p}$ 